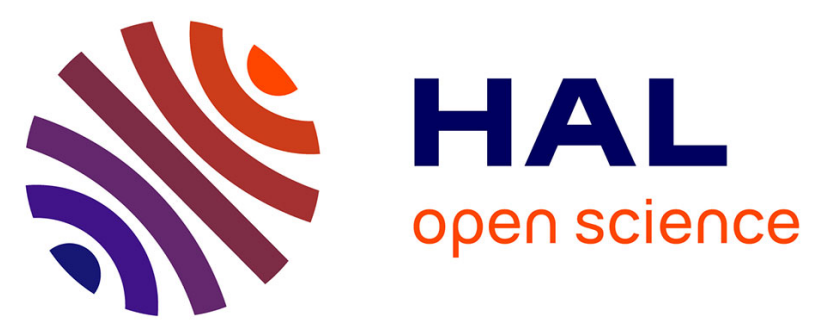

\title{
Experimental study and two-phase numerical modeling of macrosegregation induced by solid deformation during punch pressing of solidifying steel ingots
}

Takao Koshikawa, Michel Bellet, Charles-André Gandin, Hideaki Yamamura, Manuel Bobadilla

\section{To cite this version:}

Takao Koshikawa, Michel Bellet, Charles-André Gandin, Hideaki Yamamura, Manuel Bobadilla. Experimental study and two-phase numerical modeling of macrosegregation induced by solid deformation during punch pressing of solidifying steel ingots. Acta Materialia, 2017, 124, pp.513 - 527. 10.1016/j.actamat.2016.11.023 . hal-01414250

HAL Id: hal-01414250

https://hal-mines-paristech.archives-ouvertes.fr/hal-01414250

Submitted on 3 Jan 2017

HAL is a multi-disciplinary open access archive for the deposit and dissemination of scientific research documents, whether they are published or not. The documents may come from teaching and research institutions in France or abroad, or from public or private research centers.
L'archive ouverte pluridisciplinaire HAL, est destinée au dépôt et à la diffusion de documents scientifiques de niveau recherche, publiés ou non, émanant des établissements d'enseignement et de recherche français ou étrangers, des laboratoires publics ou privés. 


\title{
Experimental study and two-phase numerical modelling of macrosegregation induced by solid deformation during punch pressing of solidifying steel ingots
}

\author{
Takao Koshikawa ${ }^{1,2}$, Michel Bellet ${ }^{1}$, Charles-André Gandin ${ }^{1}$, Hideaki \\ Yamamura $^{3}$, and Manuel Bobadilla ${ }^{4}$ \\ ${ }^{1}$ MINES ParisTech, PSL Research University, CEMEF, CNRS UMR 7635, 06904 \\ Sophia Antipolis, France \\ ${ }^{2}$ Nippon Steel \& Sumitomo Metal Corporation, Oita Works Equipment Division, 1 \\ Oaza-Nishinosu, Oita City 870-0992, Japan \\ ${ }^{3}$ The Japan Institute of Metals and Materials, 1-14-32, Ichibancho, Aoba-ku, Sendai \\ 980-8544, Japan \\ ${ }^{4}$ ArcelorMittal Maizières, Research and Development, BP 30320, 57283 Maizières- \\ lès-Metz, France \\ E-mail: charles-andre.gandin@mines-paristech.fr
}

\begin{abstract}
Ingot punching tests are performed on the already formed solid shell of a $450 \mathrm{~kg}$ steel ingot during solidification. Such test is designed in order to be representative of the thermomechanical conditions that give rise to macrosegregation during secondary cooling in steel continuous casting. In order to understand the different physical phenomena, a numerical model of the test has been developed, consisting of a two-dimensional (2D) planar finite element (FE) simulation in the median section of the ingot. A two-phase formulation has been implemented, in which the velocities of the liquid and solid phases are concurrently solved for. The simulation shows how solutes are redistributed through the central mushy zone of the ingot under the effect of the compression of the solid phase and the induced fluid flow resulting from the punching of the solid shell. By comparison with measurements of macrosegregation operated on two ingots of same initial composition but punched under different conditions, the simulation proves its capacity to reproduce the main experimental trends. However the predicted intensity of macrosegregation is lower than the one measured. Through discussion and analysis of different numerical sensitivity tests, critical material parameters and model improvements are identified in view of attaining better quantitative predictions in the future.
\end{abstract}

\section{Introduction}

The paper focuses on a major defect encountered during secondary cooling in steel Continuous Casting (CC): macrosegregation. This critical defect is observed at the center of continuously cast semi-products, such as slabs and billets. Like in any solidification process, macrosegregation results from the concurrent effect of microsegregation on the one hand, and the relative movement of the liquid phase with respect to the solid phase on the other. 
Microsegregation consists of the enrichment or depletion of the liquid phase in solutes at the scale of the dendritic microstructure. As analyzed in the pioneer work by Flemings and Nereo [1], the differential liquid motion with respect to the solid may have different causes: i) the solidification shrinkage and the thermal contraction of the solid phase, ii) the convection flow of liquid arising from its local variations of density with temperature and chemical composition, iii) the movement of equiaxed solid grains transported by the liquid flow, and iv) the deformation of the solid phase within the mushy zone. In steel ingot casting, all coupled phenomena are present and play a part in the formation of macrosegregation, but the last one (iv) can often be neglected. Regarding numerical modelling, one can refer to Wu and Ludwig, Li et al. [2, 3] and Zaloznik and Combeau [4] who developed the more advanced numerical models at the present time, in the context of the finite volume method. The latter authors have also worked with two authors of the present paper to demonstrate the feasibility of finite element (FE) formulation [5].

Conversely to ingot casting, the deformation of the solid phase within the mushy zone plays a major role in continuous casting of steel. This deformation is created by the bulging of the solid shell between support rolls of the $\mathrm{CC}$ machine, which is due to the metallostatic pressure, the possible bending and unbending of the strand, and by the possible so-called "soft reduction" consisting of a mechanically applied thickness reduction of the strand operated close to the end of solidification. Such a thickness reduction of the cast product generates deformations of the underlying solid phase within the mushy zone and, as a consequence, macrosegregation. Several researchers studied these phenomena in the context of CC process with numerical modeling. Miyazawa and Schwerdtfeger [6] modelled solidification and macrosegregation, considering bulging between support rolls and the associated mushy zone deformation. In their model, mass, liquid phase momentum, solute and energy conservation equations are described in a fully Eulerian approach. The solid phase momentum equation is not solved so the velocity fields of the solid shell and of the solid phase in the central mushy region are arbitrarily given. The numerical simulation shows the formation of a center line with positive macrosegregation due to bulging. Kajitani et al. [7] studied the so-called soft reduction process using the same approach and discussed the quantitative impact of the soft reduction technique to reduce the intensity of the central macrosegregation. In a more recent contribution, Domitner et al. [8] developed a two-dimensional (2D) model covering the whole length $(25 \mathrm{~m})$ of the product in the caster, but still with a predefined motion of the solid phase, like in references [6,7]. Fachinotti et al. [10] developed a different approach to model the mushy zone in the context of $\mathrm{CC}$, using an arbitrary Lagrangian-Eulerian approach in which solid and liquid velocity fields are concurrently solved for, avoiding then the strong hypothesis over the solid velocity field which was present in previous works. With this model, the authors simulated continuous casting and similarly retrieved the effect of bulging on the formation of central macrosegregation [11]. More recently, Rivaux [12] developed an alternative approach to model the deformation of the solid phase and its Darcy-type interaction with the liquid phase in the mushy state, through a staggered scheme in which the two fields are separately and successively solved for at each time increment. However, in the end and despite lots of efforts made in developing those numerical models, none of them has been successfully applied up to the scale of a 3D simulation representative of the complexity of the industrial process. This is certainly due to the considerable amount of computational power required to run the models encompassing a significant part of the secondary cooling section of an industrial caster. 
This is one of the reasons why, in order to study and better understand the origin of the defect, experiments such as ingot bending or ingot punch pressing, have been developed by several researchers for many years [13-18]. The objective of these experiments is to analyze macrosegregation phenomena when they arise essentially from the deformation of the solid phase, and to do this in a configuration a priori simpler than continuous casting: ingot casting. This is obtained by deforming the external solid shell of an ingot during its solidification. The present study reports on an ingot punch pressing test which has been designed and operated by Nippon Steel \& Sumitomo Metal Corporation (Tokyo, Japan). In order to analyze the test, especially from the macrosegregation point of view, a FE numerical simulation has been developed using the research code R2SOL previously developed at MINES ParisTech CEMEF $[10,11]$. The paper presents the test and its application to two steel ingot of similar initial composition but punched at different times (that is for different degrees of solidification progress). Then, FE modelling of thermomechanics and solute transport is introduced. Finally, results are presented and the predicted occurrence, location, and intensity of macrosegregation are explained and discussed in the light of experimental measurements.

\section{Ingot punch pressing test}

The schematic of the ingot punch pressing test, as developed at Nippon Steel \& Sumitomo Metal Corporation, is shown in Figure 1. It has been designed to mimic the thermomechanical loads taking place during CC process; for instance, with respect to the evolution of the cooling rate and deformation. The procedure of the experiment is as follows: the molten metal is prepared in an electric ladle furnace and the temperature is maintained at $1640{ }^{\circ} \mathrm{C}$ before pouring. The molten metal is poured into the mold from the top through a tundish. The filling duration is about $70 \mathrm{~s}$. After filling, powder is added at the top of the ingot to limit heat exchanges with air. The mass of metal is approximately $450 \mathrm{~kg}$. The size of the ingot is 0.16 $\mathrm{m}$ in thickness, $0.5 \mathrm{~m}$ in width and $0.75 \mathrm{~m}$ in height. In practice, a fibrous thermal insulator of thickness $5 \mathrm{~mm}$ covers the inner walls of the lowest part of the mold up to $0.2 \mathrm{~m}$ from the bottom of the ingot in order to avoid molten metal sticking. At a precise time after filling, the upper part of one of the two large faces of the mold is removed, as illustrated in the right part of Figure 1b. The ingot is then deformed during solidification by pushing a horizontal cylindrical tool perpendicularly to the surface of the ingot, its longitudinal axis being located $0.45 \mathrm{~m}$ from the bottom of the ingot. The tool velocity and displacement are controlled by means of a hydraulic system and measured during the test. The reaction force is also measured using the time evolution of the hydraulic system pressure.

For the alloy targeted in the present work, a total of 9 experiments, labelled N-1 to N-9 were performed. They belong to a series that aims at studying both macrosegregation and hot tearing sensitivity as these defects are frequently found to form concomitantly [19]. However, due to very demanding efforts to analyze and present the trials with respect to macrosegregation, only the test conditions referred to as N-1 and N-9 are considered in the present work. Parameters are summarized in Table 1, together with measured nominal compositions in the ladle before filling. Note that a unique alloy composition was targeted for the experimental results reported hereafter. The two tests differ first by the time at which the punching starts. For N-1 punching starts earlier on a central mushy zone richer in liquid. 
Conversely, for N-9, solidification is more advanced at the beginning of punching. Tests show also differences in punch displacement, the maximum punch force being limited to $450 \mathrm{kN}$ for the protection of the bending equipment. In case N-9, this limiting punch force is obtained for a displacement of $9 \mathrm{~mm}$, after which the punch stops. In case N-1, which is a priori less resistant, due to a less advanced solidification, the limiting force is obtained for a larger displacement of $13 \mathrm{~mm}$. The temperature evolution during the test is recorded by a B-type thermocouple positioned in the ingot cavity, as shown in Figure 1a. For the thermocouple setting, a hole along horizontal direction, of diameter $5 \mathrm{~mm}$, is pierced through the fixed large face of the mold. A thermocouple is inserted into the hole from outside and is placed at the desired position. For sealing purpose, a thermal insulator is put into the hole after setting of the thermocouple.

After the experiment, ingots were cut along their central transverse symmetry plane and micrographs were carried out after appropriate etching. Figure 2 shows micrographs for both trials $\mathrm{N}-1$ and N-9. The punching tool moves from the right to the left and the surface deformation due to punching appears clearly. Concerning microstructure, one can see a dendritic columnar microstructure which has grown from the ingot surface toward the center. Note that the primary trunk of the dendritic structure is slightly oriented upward. This is expected when considering liquid melt thermal convection oriented downward in front of the growing dendrites. Because the direction of dendrite trunks and arms correspond to $<100>$ crystallographic directions in the present system, a texture of the columnar zone is thus defined. Further recirculation of the liquid in the mushy zone will no longer modify this texture settled during primary solidification. Around the center of the ingot, the morphology is changed to equiaxed due to the decrease of the temperature gradient close to the center of the ingot. At the top, primary shrinkage shape is observed and a macro void is also found below the very thin top solid shell. In order to avoid thermal exchange at the top, powder is put after filling. However, the thermal exchange is not completely prevented. So, a thin solid shell is formed at the top and the macro void is then generated below, due to shrinkage. Looking at the bottom of the micrographs, the morphology is almost of equiaxed type due to the same reason. This is associated here with the presence of the thermal insulator along the bottom surface to avoid sticking; its presence being made visible by the shape of the ingot transverse section at bottom and up to approximately $200 \mathrm{~mm}$ height. Because of the thermal insulation, solidification is delayed, compared to the top area. Close to the end of ingot solidification the liquid melt cannot be provided from the upper central regions due to earlier completion of solidification there. In the end, a macro void necessarily forms because of shrinkage as shown in Figure 2 at about $150 \mathrm{~mm}$ height from the bottom of the ingot. The vertical white band at the ingot center reveals negative segregation. It appears very clearly so that the solute variation could be large, especially for test N-1. For quantitative analysis, Electron Probe Micro Analyzer (EPMA) measurements were performed on both ingots, for species $\mathrm{Mn}$ and P. Measurement conditions were as follows: beam diameter $50 \mu \mathrm{m}$, beam current $1 \mu \mathrm{A}$, integration time $50 \mathrm{~ms}$, measurement step $50 \mu \mathrm{m}$. Line scan measurements were carried out along a horizontal line at punch height. For comparison to numerical simulation results, the measurement values were averaged over $2 \mathrm{~mm}$ where 40 measurement points are contained and the standard deviations were calculated at each average point. Results will be presented further (Section 4), together with the predicted macrosegregation profiles, for comparison purposes. 


\section{Thermomechanical and macrosegregation FE modeling}

\section{1. "Two-phase" thermomechanical and macrosegregation modeling}

The macrosegregation formed in such a punch pressing test clearly results from the concurrent deformation of the solid phase in the mushy zone, and from the liquid flow induced by this deformation. In order to consider separately - but solve concurrently - for the liquid and solid velocity fields in the mushy zone, we apply the so-called "two-phase" model initially developed by Bellet et al. $[10,11]$ to address macrosegregation in continuous casting. This model is also named "sponge-like" model by reference to the title of the paper of Lesoult et al. [9] in which the balance equations governing the deformation of an alloyed mushy zone were expressed. This model allows simulating solute transport phenomena leading to macrosegregation induced by deformation, shrinkage and advection. It is performed with the 2D FE code R2SOL. The main assumptions and features of the model are reminded hereafter.

- The conservation equations for the solid-liquid mixture are expressed on a representative elementary volume (REV) and are obtained using the spatial averaging method [20]

- The mushy material is considered as a saturated two-phase medium only made of solid, $\mathrm{s}$, and liquid, 1 (i.e. $g_{s}+g_{l}=1$ where $g_{k}$ denotes the volume fraction of phase $k$ ).

- At the so-called microscopic scale, within the REV, the liquid phase is considered as an incompressible Newtonian fluid. After spatial averaging, the macroscopic behavior of the liquid phase is Newtonian compressible.

- In the same way, the solid phase is considered intrinsically as an incompressible nonNewtonian fluid, and its macroscopic averaged behavior is the one of a compressible nonNewtonian fluid for which inertia effects are neglected.

- The momentum interaction between solid and liquid phases is formulated with an isotropic Darcy law.

- Solidification shrinkage is taken into account by considering different densities for the solid and liquid phases, respectively $\rho_{S}$ and $\rho_{L}$. Those values are assumed constant within the solidification interval using the value at the liquidus temperature for $\rho_{L}$ and the value at the solidus temperature for $\rho_{S}$, the latter being the volume-average of the density of all solid phases.

- A multi component system under lever rule approximation is assumed, meaning that the partition coefficient $k_{i}$ and the liquidus slope $m_{i}$ are constant for each solute element $i$.

- Local thermal equilibrium holds within the REV, ensuring the uniformity of temperature within the different phases.

The previous assumptions lead to the following set of averaged conservation equations:

$$
\begin{aligned}
& \nabla \cdot \boldsymbol{\Sigma}^{s}-g_{s} \nabla p_{l}+g_{l}{ }^{2} \mu_{l} \kappa^{-1}\left(\mathbf{v}_{l}-\mathbf{v}_{s}\right)+g_{s} \rho_{S} \mathbf{g}=0 \\
& \nabla \cdot\left\langle\mathbf{s}^{l}\right\rangle-g_{l} \nabla p_{l}-g_{l}{ }^{2} \mu_{l} \kappa^{-1}\left(\mathbf{v}_{l}-\mathbf{v}_{s}\right)+g_{l} \rho_{L} \mathbf{g}=\rho_{L} \frac{\partial\left(g_{l} \mathbf{v}_{l}\right)}{\partial t}+\rho_{L} \nabla \cdot\left(g_{l} \mathbf{v}_{l} \times \mathbf{v}_{l}\right)
\end{aligned}
$$




$$
\begin{aligned}
& \nabla \cdot\left(g_{l} \mathbf{v}_{l}\right)+\frac{\rho_{S}}{\rho_{L}} \nabla \cdot\left(g_{s} \mathbf{v}_{s}\right)=\left(\frac{\rho_{L}-\rho_{S}}{\rho_{L}}\right) \frac{\partial g_{s}}{\partial t} \\
& \langle\rho\rangle \frac{\partial\langle h\rangle}{\partial t}+\nabla\langle h\rangle \cdot\langle\rho \mathbf{v}\rangle+L \nabla \cdot\left(g_{l} g_{s}\langle\rho\rangle\left(\mathbf{v}_{l}-\mathbf{v}_{s}\right)\right)-\nabla \cdot(\langle\lambda\rangle \nabla T)=0 \\
& \frac{\partial\left\langle w_{i}\right\rangle}{\partial t}+\nabla \cdot\left(\left\langle w_{i}\right\rangle \mathbf{v}_{s}\right)+\nabla \cdot\left(g_{l} w_{l, i}\left(\mathbf{v}_{l}-\mathbf{v}_{s}\right)\right)-\nabla \cdot\left(g_{l} D_{l} \nabla w_{l, i}\right)=0
\end{aligned}
$$

in which $\mathbf{v}_{s}$ and $\mathbf{v}_{l}$ are the solid and liquid velocity vectors (intrinsic average phase velocities: $\left.\mathbf{v}_{l} \equiv\left\langle\mathbf{v}^{l}\right\rangle^{l} ; \mathbf{v}_{s} \equiv\left\langle\mathbf{v}^{s}\right\rangle^{s}\right), p_{l}$ is the liquid phase pressure $\left(p_{l} \equiv\left\langle p^{l}\right\rangle\right), \mu_{l}$ is the dynamic viscosity of the liquid phase, $\langle\rho\rangle$ and $\langle\lambda\rangle$ are the average density and the average heat conductivity of the solid-liquid mixture, $\langle h\rangle$ is the average enthalpy of the mixture. $\left\langle w_{i}\right\rangle$ and $w_{l, i}$ are respectively the average solute mass concentration and the intrinsic average concentration in the liquid phase for each solute $i$. In the momentum equations, the Darcy term introduces the permeability $\kappa$ of the porous medium constituted by the solid phase. It is derived from the liquid volume fraction and the secondary dendrite arm spacing $\lambda_{2}$, through the Carman-Kozeny model.

$$
\kappa=\frac{\lambda_{2}^{2} g_{l}^{3}}{180\left(1-g_{l}\right)^{2}}
$$

Constitutive models for the liquid and the solid phases in the mushy zone are presented in detail in references $[10,11]$. In summary, the average deviatoric stress tensor in the liquid phase is expressed by:

$$
\left\langle\mathbf{s}^{l}\right\rangle=2 \mu_{l} g_{l} \operatorname{dev}\left(\dot{\boldsymbol{\varepsilon}}\left(\mathbf{v}_{l}\right)\right)=2 \mu_{l} g_{l}\left(\dot{\boldsymbol{\varepsilon}}\left(\mathbf{v}_{l}\right)-\frac{1}{3} \operatorname{tr}\left(\dot{\boldsymbol{\varepsilon}}\left(\mathbf{v}_{l}\right)\right)\right)
$$

where $\dot{\boldsymbol{\varepsilon}}\left(\mathbf{v}_{l}\right)$ is the symmetric part of the liquid velocity gradient $\nabla \mathbf{v}_{l}$. For solid, it is assumed that the behavior of the fully solid material is viscoplastic, of power law type, as will be introduced later. The strain-rate sensitivity coefficient of the fully solid material being denoted $m$, it can be shown that the effective macroscopic stress tensor for the solid phase in the mushy state, $\Sigma^{s}=\langle\boldsymbol{\sigma}\rangle+p_{l} \boldsymbol{I}$, is a degree $m$ homogeneous function with respect to the strain rate tensor $\langle\dot{\boldsymbol{\varepsilon}}\rangle^{s}=\dot{\boldsymbol{\varepsilon}}\left(\boldsymbol{v}_{s}\right)$. Adopting a compressible viscoplastic potential, its expression writes:

$$
\begin{aligned}
\Sigma^{s} & =3 K\left(\sqrt{3}\langle\dot{\bar{\varepsilon}}\rangle^{s}\right)^{m-1}\left(\frac{1}{A}\langle\dot{\boldsymbol{\varepsilon}}\rangle^{s}+\left(\frac{1}{9 B}-\frac{1}{3 A}\right) \operatorname{tr}\langle\dot{\boldsymbol{\varepsilon}}\rangle^{s} \mathbf{I}\right) \\
& =3 K\left(\sqrt{3}\langle\dot{\bar{\varepsilon}}\rangle^{s}\right)^{m-1}\left(\frac{1}{A} \operatorname{dev}\left(\langle\dot{\boldsymbol{\varepsilon}}\rangle^{s}\right)+\frac{1}{9 B} \operatorname{tr}\langle\dot{\boldsymbol{\varepsilon}}\rangle^{s} \mathbf{I}\right)
\end{aligned}
$$

in which $K$ is the viscoplastic consistency of the solid material and $m$ its strain rate sensitivity, both taken at the solidus temperature. The equivalent strain rate $\langle\dot{\bar{\varepsilon}}\rangle^{s}$ is expressed by 


$$
\begin{aligned}
\langle\dot{\bar{\varepsilon}}\rangle^{S} & =\left(\frac{1}{A}\langle\dot{\boldsymbol{\varepsilon}}\rangle^{s}:\langle\dot{\boldsymbol{\varepsilon}}\rangle^{S}+\left(\frac{1}{9 B}-\frac{1}{3 A}\right)\left(\operatorname{tr}\langle\dot{\boldsymbol{\varepsilon}}\rangle^{s}\right)^{2}\right)^{\frac{1}{2}} \\
& =\left(\frac{1}{A} \operatorname{dev}\left(\langle\dot{\boldsymbol{\varepsilon}}\rangle^{S}\right): \operatorname{dev}\left(\langle\dot{\boldsymbol{\varepsilon}}\rangle^{s}\right)+\frac{1}{9 B}\left(\operatorname{tr}\langle\dot{\boldsymbol{\varepsilon}}\rangle^{S}\right)^{2}\right)^{\frac{1}{2}}
\end{aligned}
$$

In the flow rule (Eq. (8)), $A$ and $B$ are two coefficients depending on the solid volume fraction. In the present study, the expressions introduced in reference [10] are used:

$$
B=k_{B} \frac{1-g_{s}}{g_{s}-g_{s}^{c r i t}} \quad A=\frac{3}{2}\left(1+k_{A} B\right)
$$

The values of the parameters are taken from the same reference. Taking the trace of Eq. (8), it can be seen that the compressibility of the solid phase is essentially controlled by the value of coefficient $B$ :

$$
\operatorname{tr} \Sigma^{s}=K\left(\sqrt{3}\langle\dot{\bar{\varepsilon}}\rangle^{s}\right)^{m-1} \frac{1}{B} \operatorname{tr}\langle\dot{\boldsymbol{\varepsilon}}\rangle^{s}
$$

As expressed by Eq. (10a), $g_{s}^{\text {crit }}$ can be seen as the coherency temperature at which the compressibility of the solid phase is extremely high $(B \rightarrow \infty)$. Conversely, when the solid fraction tends to one (fully solid material), $A$ and $B$ tend toward $3 / 2$ and 0 , respectively: the usual power law relating stress and strain rate for a dense metal at high temperature is retrieved.

In the FE code, the weak (integral) form of Eqs (1) to (5) is implemented in 2D triangular finite elements. At each time increment, the sequence of numerical resolutions is as follows:

- The thermal resolution is operated on the set of the different domains involved: in the present context, the solidifying ingot, the different components of the mold, and the pressing punch. The (non-linear) heat transfer resolution is carried out on each domain, successively, up to convergence (i.e. stabilization of the temperature field). In the ingot, a FE resolution of Eq. (4) is done, while in the other domains a more classical single phase form of heat diffusion is solved. Heat exchanges at interfaces between domains are expressed by the Fourier law, using heat transfer coefficients.

- The macrosegregation resolution is performed in the ingot, through a FE resolution of Eq. (5) for each considered solute $i$. In these resolutions, like in the thermal one, the microsegregation model (here the lever rule) is considered as it links the average concentrations in the liquid phase $w_{l, i}$ with the average mixture concentrations $\left\langle w_{i}\right\rangle$, and the averaged enthalpy $\langle h\rangle$ with the temperature $T$.

- The mechanical resolution is performed in the ingot, the other domains being assumed perfectly rigid and fixed. A non-linear Newton-Raphson algorithm is used, providing the nodal values of $\mathbf{v}_{s}, \mathbf{v}_{l}$ and $p_{l}$ through a single FE resolution of Eqs (1) to (3). As the mechanical formulation presented above encompasses the central mushy zone but also the fully solidified regions, a specific treatment applies. In the FE assembly procedure, 
elements are considered either mushy or fully solid, according to the temperature at their center. In mushy elements, the contribution to the residue directly results from the weak form of Eqs (1) to (3). In fully solid elements, it can be noted that, by applying these equations, the liquid velocity is still present but has no real physical meaning: it is then kept close to the solid velocity field by means of the sole Darcy term in the liquid momentum equation, acting as a penalty term. The deviatoric stress tensor $\mathbf{s}$ is expressed as a function of the velocity field by the viscoplastic Norton-Hoff power law including strain hardening:

$$
\mathbf{S}=2 K \bar{\varepsilon}^{n}(\sqrt{3} \dot{\bar{\varepsilon}})^{m-1} \operatorname{dev}(\dot{\boldsymbol{\varepsilon}})
$$

where $\operatorname{dev}(\dot{\boldsymbol{\varepsilon}})$ denotes the deviatoric part of the strain rate tensor, $K$ the viscoplastic consistency, $m$ the strain rate sensitivity coefficient, $\dot{\bar{\varepsilon}}$ the generalized strain rate and $\bar{\varepsilon}$ the generalized strain. Strain-hardening is assumed null at solidus temperature. This is why only $K$ (and not $K \bar{\varepsilon}^{n}$ ) appears in Eq.(8) to express the behavior model of the solid phase in the mush. The tensor equation (12) yields the one dimensional relation between the von Mises stress $\bar{\sigma}$ and the generalized strain-rate $\dot{\bar{\varepsilon}}$ :

$$
\bar{\sigma}=K(\sqrt{3})^{m+1} \bar{\varepsilon}^{n} \dot{\bar{\varepsilon}}^{m}
$$

The fully solid metal is then plastically incompressible and this is why, in the finite elements which are found fully solid (temperature at center lower than the solidus temperature), Eq. (3) is replaced by the following equation which simply accounts for thermal dilatation terms:

$$
\nabla \cdot \mathbf{v}_{s}+\frac{1}{\rho_{s}(T)} \frac{\mathrm{d} \rho_{s}(T)}{\mathrm{d} t}=0
$$

\subsection{Specific modeling of ingot punch pressing test}

The numerical simulation is two dimensional, in plane strain conditions, along the transverse mid-section of the casting system. Such a 2D approach seems a priori reasonable to analyze the results produced in this symmetry plane, the width of the ingot $(500 \mathrm{~mm})$ being more than 3 times greater than its thickness $(160 \mathrm{~mm})$. As illustrated in Figure 1, 7 domains are involved: the ingot, 5 mold components, and the punch. The base mesh size is $8 \mathrm{~mm}$ but the punching region of the ingot is refined up to $2 \mathrm{~mm}$ and the number of elements in the ingot is approximately 40,000. The filling stage is not taken into account so that the simulation starts immediately after the end of filling, that is $70 \mathrm{~s}$ after its start. The temperature of the liquid steel at that time is supposed to be homogeneous in the ingot domain. According to measurements, it is estimated to $1550{ }^{\circ} \mathrm{C}$. Temperature is supposed uniform and equal to $20^{\circ} \mathrm{C}$ for all other domains. The thermal boundary condition between ingot and mold components is defined as a constant heat transfer coefficient which is calibrated with measurement and set to $550 \mathrm{~W} \mathrm{~m}^{-2} \mathrm{~K}^{-1}$. Regarding the ingot top, an adiabatic condition is used, modeling the powder thermal insulator. After partial mold removal, the free surface heat 
exchange takes into account radiation and convection, with values for emissivity and convective heat transfer coefficient taken as 0.8 and $15 \mathrm{~W} \mathrm{~m}^{-2} \mathrm{~K}^{-1}$, respectively.

It has been underlined above that the "two-phase" solid-liquid FE model can be extended to the fully solidified metal. However, the extension to the fully liquid state is not possible. This is the reason why the simulation is actually decomposed in two successive steps, as described hereafter.

- In a first simulation step, started at time $70 \mathrm{~s}$, a "standard" thermomechanical calculation is conducted up to the moment of punching. In this first calculation, solute transport resolution is not carried out because the mushy zone is considered as a homogenized continuum in which solid and liquid velocities are not distinguished. Instead, the mush is supposed to behave like an homogenized non-Newtonian fluid with a viscoplastic consistency and a strain-rate sensitivity varying with the sole solid fraction. The nature of the FE modelling operated is not detailed here and can be found in references [21,22]. During this simulation step, solidification is governed by a unique solidification path which is defined a priori by the lever rule, based on the nominal steel composition. This solidification path is shown in Figure 3 (see details hereunder), the liquidus temperature being $1511^{\circ} \mathrm{C}$ and the solidus $1412^{\circ} \mathrm{C}$.

- A second simulation step is then chained to the previous one, through an automatic restart procedure including the transmission of the spatial distribution of all required variables. In this second step the "two-phase" model presented above (Section 3.1) now applies. At this moment, just before punching, the solidification of the ingot is significantly advanced and the central region of the ingot is fully in the mushy state, without any region containing liquid phase only. In the ingot domain, the simulation covers then the central mushy zone and the solidified shell, and is run up to complete solidification of the ingot, in order to compare macrosegregation profiles with EPMA measurements. During this second simulation step, the solidification path is no more defined a priori, since solutes concentrations vary due to liquid flow and solid deformation. Given a multicomponent system involving $N_{S}$ solutes, the lever rule approximation is used to model the microsegregation phenomena. Assuming constant partition coefficients $k_{i}$ and liquidus slopes $m_{i}$ for each solute element $i$, one obtains the following relations:

$$
\begin{aligned}
& T=T_{m}+\sum_{i=1}^{N_{S}} m_{i} w_{l, i} \\
& \left\langle w_{i}\right\rangle=\left(g_{l}+\left(1-g_{l}\right) k_{i}\right) w_{l, i} \\
& \langle h\rangle=c_{p} T+g_{l} L
\end{aligned}
$$

where $T_{m}$ is the melting temperature of pure iron, $c_{p}$ is the heat capacity (assumed constant in the present study), and $L$ is the latent heat (also assumed constant). The number of equations is $N_{S}+2$. The average quantities $\langle h\rangle$ and $\left\langle w_{i}\right\rangle$ are known since these variables are obtained thanks to the global energy and solutes conservation resolutions. The number of unknowns is then $N_{S}+2: T, g_{l}$ and $w_{l, i}$. Thus, the set of equations is well posed and can be solved iteratively at each node of the mesh. The required characteristic solutal coefficients $k_{i}$ and $m_{i}$ are obtained using Thermo-Calc with TCFE6 database [23, 24]: their 
values are given in Table 2, for each of the 5 solutal elements which are considered here: $\mathrm{C}, \mathrm{Si}, \mathrm{Mn}, \mathrm{P}$ and $\mathrm{S}$. The melting temperature for pure iron is defined as $1538{ }^{\circ} \mathrm{C}$. The constant values of the specific heat $c_{p}$ and of the latent heat $L$ are $815 \mathrm{~J} \mathrm{~kg}^{-1} \mathrm{~K}^{-1}$ and $260000 \mathrm{~J} \mathrm{~kg}^{-1}$, respectively. With the nominal composition, i.e. in the absence of macrosegregation, one can obtain the solidification path shown in Figure 3. When proceeding to the initialization of nodal variables at the beginning of this second simulation step, at each node the average concentrations $\left\langle w_{i}\right\rangle$ are set to the nominal ones $w_{i 0}$. Then, knowing $\langle h\rangle$ from the first simulation step, a first calculation of $T, g_{l}$ and $w_{l, i}$ is carried out by solving Eqs (15)-(17).

Regarding now the mechanical data, Figure 4 shows a comparison between experimental stress-strain plots, obtained by tensile tests performed at different high temperatures and various strain rates, and calculated curves based on Eq. (13) for optimized values of $K, n$ and $m$ coefficients identified by regression analysis. The comparison indicates a good agreement over the whole set of conditions tested. The temperature dependence of the constitutive parameters is shown in Figure 4(c). As regards the liquid viscosity, it is defined arbitrarily as $0.005 \mathrm{~Pa} \mathrm{~s}[7,8]$. In the Darcy term the permeability of the Carman-Kozeny model considers a constant predefined value of $300 \mu \mathrm{m}$ for the secondary dendrite arm spacing $\lambda_{2}$, on the basis of measurements carried out on micrographs in case N-1. Finally, the heat conductivity and the density, as used in Eqs (3) and (14) for the latter, are shown in Figure 5. Densities were obtained by use of Thermo-Calc software and TCFE6 database assuming full equilibrium solidification path [23, 24], while the temperature dependence of thermal conductivity was taken from the literature [27].

\section{Results and discussion}

\subsection{Micrographs for the two trials}

Coming back to Figure 2, showing micrographs for the two ingots, we note two important differences between N-1 and N-9. First of all, the clear vertical white band observed in case of $\mathrm{N}-1$ is not observed in N-9. Secondly, the microstructure in the top region is found different. In case of $\mathrm{N}-1$, a darker microstructure is observed, well delimited and located at the bottom of the main shrinkage pipe. It seems to partially fill the initially formed pipe cavity. This is not seen in the shrinkage cavity of $\mathrm{N}-9$. Those differences are interpreted in the following section.

\subsection{Numerical simulation of trials $N-1$ and N-9: heat transfer and mechanical analysis}

Figure 6 shows a comparison of temperature evolutions close to the ingot center. It is seen that the two cooling histories measured by thermocouples for trials $\mathrm{N}-1$ and $\mathrm{N}-9$ are quite close, indicating a good reproducibility obtained through an appropriate control of the procedures of mold preparation and casting. A small deviation between the two tests can be seen after $800 \mathrm{~s}$, but this occurs after the punching stage and should not affect the quantitative comparison of macrosegregation. 
The calculated curve shown in the figure has been obtained by the "standard" thermomechanical simulation presented above and is in good agreement with the measurements, especially during the punching stage (starting at $792 \mathrm{~s}$ for $\mathrm{N}-1$, and at $881 \mathrm{~s}$ for $\mathrm{N}-9)$. This good agreement is maintained up to full solidification, which is obtained after 900 $\mathrm{s}$, according to the numerical simulation. This expresses a good quality of the set of thermophysical data used in the simulation, as well as a good calibration of heat exchange at interfaces. The state of the ingot just before punching, as simulated by the "standard" thermomechanical simulation in the first simulation step defined above, can be visualized in Figure 7.

It can be seen that at that time, solidification is quite advanced. Table 3 contains quantitative information on temperature and the maximum of liquid fraction at the core of the ingot. In case of $\mathrm{N}-1$, we note that the calculated liquid fraction is higher (0.39) than for $\mathrm{N}-9$ (0.12). This is of course consistent with the fact that punching is activated earlier in case $\mathrm{N}-1$ (792 s) than for N-9 (881 s) as reported in Table 1.

Let's consider now the deformation of the solid phase and the associated liquid flow, as calculated in the "two-phase" approach. This is illustrated in Figure 8, for the simulation of trial N-1. The deformation of the solid shell by the punch induces a compression of the solid phase in the mushy zone (not visible in Figure 8), which in turn induces liquid flow. For evident reasons (global quasi incompressibility of the mushy material, closed mushy pool at the bottom of the ingot), liquid flow is necessarily oriented upward. In case $\mathrm{N}-1$, solidification is less advanced. The alloy is still in the mushy state in its top central region. This makes possible such an upward liquid flow, with liquid expulsion at the top surface into the primary shrinkage cavity: the expelled melt covers the already formed solid shell. The simulated liquid flow can be seen in the central part of Figure 8. Experimental evidence of such an expulsion of liquid flow is provided by the micrograph on the right part of the figure, in which a residue of enriched (darker) expelled liquid is present at the bottom of the wedge-shaped shrinkage cavity. It is interesting to compare the shape of the shrinkage cavity between simulation and micrograph. Of course the real ingot shows a complex form, especially with a residual thin skin at the extreme top, which results from a complex thermomechanical interaction with the cover powder. This is not simulated. However, the section of the wedge-shape at the lower surface of the cavity is well reproduced by the thermo-mechanical simulation.

Figure 9 reveals in more details what happens in the mushy zone at the height of the punch tool. Due to the motion of the punching tool, the solid shell in its vicinity is displaced as shown by the horizontal component of the solid velocity (Figure 9(a)). The resulting compression of the solid phase within the mushy zone is expressed by negative values of the divergence of the solid velocity field, $\nabla \cdot \mathbf{v}_{s}$, displayed in Figure 9(b). A relative liquid flow is thus created as shown in in Figure 9(c). The compression of the solid phase primarily affects the regions of the mush for which the liquid fraction is higher than 0.1 . Indeed, when liquid fraction decreases, the value of coefficient $B$, which controls the compressibility of the solid phase (cf. Eq. (11)), decreases as well, tending towards zero which is the limit of the $B$ value associated with a fully dense solid material. This continuous decrease of coefficient $B$ hinders the compression of the solid phase at the periphery of the mushy zone, where solidification is more advanced. 
Considering the mass balance equation, Eq. (3), and taking into account that advancement of solidification described by the right hand side term is much lower than $\nabla \cdot\left(g_{s} \mathbf{v}_{s}\right)$, the compression of the solid phase $\left(\nabla \cdot\left(g_{s} \mathbf{v}_{s}\right)<0\right)$ creates a liquid flow. Because of the presence of the solid shell, this liquid flow is severely constrained along the horizontal direction. Therefore it is found essentially vertical but showing a positive velocity gradient along the vertical direction, thus ensuring $\nabla \cdot\left(g_{l} \mathbf{v}_{l}\right)>0$. Accordingly, the flow of the liquid phase is accelerated vertically. This resulting flow can be seen in Figure 9(c). Note that there is no "neutral point" in front of the punch inside the mushy zone, which would separate an upper region with upward $\mathbf{v}_{l}$ from a lower region with a downward $\mathbf{v}_{l}$. As mentioned earlier, this is because of the closure of the mushy pool at the bottom of the ingot, where the solid shell cannot move, being blocked by the mold. For this reason, the liquid velocity field is uniformly oriented upward throughout the whole mushy zone, but with a vertical gradient in order to comply with the compression of the liquid skeleton through the mass balance equation (Eq. (3)).

Looking now at two different instants during punching, like in Figure 10 at 1 and $4 \mathrm{~s}$ after punch start, it can be seen that the distribution of liquid fraction has changed significantly, showing a general decrease and a shift towards the opposite side to the punch (here, a shift to the left). Different phenomena contribute to the evolution of the liquid fraction.

- First, the global solidification of the ingot explains a general decrease of the liquid fraction, which should be found more or less symmetric. Looking at the left side of the mushy zone, this phenomenon is found negligible on the time interval considered: the isolines 0.1 and 0.2 for the liquid fraction are stationary.

- Second, the chill effect due to the contact with the punch. The cooling associated with the heat extraction through the punch can be seen in Figure 11. This effect is nonsymmetric but has no significant influence on the core of the ingot. Indeed, a quick estimation of the affected distance (through the expression $\sqrt{\alpha \Delta t}$ where $\alpha$ is the thermal diffusivity of the material and $\Delta t=3 \mathrm{~s}$ ) leads to a distance of about $4 \mathrm{~mm}$ : the chill effect only affects the skin of the ingot, as shown in Figure 11.

- Third, the motion of the solid phase, which is compressed and pushed toward the left direction as a consequence of the displacement of the solid shell induced by the motion of the punch. The punch velocity being $2 \mathrm{~mm} / \mathrm{s}$, the $6 \mathrm{~mm}$ displacement of the solid shell to the left can be seen through the displacement of the isolines 0 and 0.1 for the liquid fraction on the right side of the mushy zone. Clearly this effect is dominant. It also induces the expulsion of the liquid phase, because of mass conservation (Eq. (3)).

At time $4 \mathrm{~s}$ after punch start (Figure 10(b)), the liquid velocity is more or less maintained, which is normal since the punch keeps moving (total duration of the motion: $6.5 \mathrm{~s}$ in case $\mathrm{N}-1$ ). However, the liquid flow appears to be more uniform through the thickness of the mushy zone than at time $1 \mathrm{~s}$ (Figure 10(a)). To understand this, one has to consider again the expression of coefficient $B$. It is maximum in the center of the mushy zone (where $g_{s}$ is minimum) and continuously decreases up to the boundary of the mushy zone, where it takes the value zero. Therefore, upon combined forced movement of the solid phase and solidification, the maximum value in the center continuously decreases, and so the module of the gradient of $B$ through the mushy zone. This expresses that the compressibility of the solid 
phase becomes more and more uniform throughout the thickness of the mushy zone. As a consequence, the amplitude of the values of $\nabla \cdot \mathbf{v}_{s}$ decreases, and so the amplitude of $\nabla \cdot \mathbf{v}_{l}$. Finally, that explains a decrease in the liquid velocity gradient through the thickness of the mush, as shown in Figure 10(b).

Over the punching region, the compression of the solid phase decreases rapidly with height as it can be seen in Figure 9(b). As a consequence, in this region, the liquid flow coming from the lower regions of the mush is distributed in the mush according to the permeability, as shown in Figure 12. That explains higher velocities in the center, where permeability is the highest, while liquid flow is found much slower at the periphery of the mushy zone, where permeability is lower.

In the case of trial $\mathrm{N}-9$, punching is triggered later in the ingot solidification. As indicated in Table 3, the maximum liquid fraction at ingot center is here limited to 0.12. Consequently, both the compressibility and the permeability of the solid phase are much lower than in case $\mathrm{N}-1$. Therefore, relative velocity of the liquid flow with respect to the solid is very low. This is illustrated in Figure 13. The mushy material tends to behave like a homogenized material in which the two phases have approximately the same velocity field. This velocity field is determined by the global incompressibility of the mush and by the displacement/deformation induced by the punch motion. In case of $\mathrm{N}-1$ at $4 \mathrm{~s}$ after punch start, the maximum relative velocity at the punch height is around $0.02 \mathrm{~m} \mathrm{~s}^{-1}$, while in case of $\mathrm{N}-9$, it is about $0.002 \mathrm{~m} \mathrm{~s}^{-1}$ which is the same order of magnitude of punch velocity. Concerning the divergence of solid velocity, its value in case of N-4 is $-0.04 \mathrm{~s}^{-1}$ and it is $-0.007 \mathrm{~s}^{-1}$ in case of N-9.

\subsection{Macrosegregation analysis}

According to the numerical simulation described in the previous section, the remaining liquid in the mushy zone, which is enriched with solutes, is transported from the punching tool height to the ingot top. This is combined with the compression of the solid phase, and the local increase of solid fraction at punch height. From this, a negative macrosegregation is expected to take place at the ingot center, as it is effectively shown by the micrographs (see Figure 2(a)). Let's analyze the numerical simulation of the formation of macrosegregation in more detail before making quantitative comparisons.

Figure 14 shows the progression of the macrosegregation of manganese upon punching. To understand this formation, let's come back to the nature of the governing equation (Eq. (5)) and to its numerical treatment. First, in the simulation, the FE nodes are updated according to the velocity of the solid phase, what is expressed by $\mathbf{v}_{m s h}=\mathbf{v}_{s}$ where $\mathbf{v}_{m s h}$ is the mesh velocity. Consequently, the time partial derivative of the solute concentration, which is the first term in Eq. (5), can be written as (for the sake of simplicity, the solute index $i$ is omitted here):

$$
\frac{\partial\langle w\rangle}{\partial t}=\frac{\partial_{m s h}\langle w\rangle}{\partial t}-\nabla\langle w\rangle \cdot \mathbf{v}_{s}
$$


where $\partial_{m s h} / \partial t$ denotes the time derivation with respect to the mesh, that is when following grid nodes (or, equivalently, following the solid phase). After injection in Eq. (5) we get:

$$
\frac{\partial_{m s h}\langle w\rangle}{\partial t}=\underbrace{\nabla \cdot\left(g_{l} D_{l} \nabla w_{l}\right)}_{\text {diffusion }}-\underbrace{\nabla w_{l} \cdot\left(g_{l}\left(\mathbf{v}_{l}-\mathbf{v}_{s}\right)\right)}_{\text {advection }}-\underbrace{\left(w_{l} \nabla \cdot\left(g_{l}\left(\mathbf{v}_{l}-\mathbf{v}_{s}\right)\right)+\langle w\rangle \nabla \cdot \mathbf{v}_{s}\right)}_{\text {compression of solidphase }}
$$

The different contributions to the formation of macrosegregation can then be clearly identified: diffusion in the liquid phase, transport (advection) due to the relative velocities of liquid and solid phase, compression of the solid phase. Owing to the very low diffusion coefficient $D_{l}$, of the order of $10^{-9} \mathrm{~m}^{2} \mathrm{~s}^{-1}$, the contribution of diffusion is marginal. The second contribution is also quite limited in the present situation because the gradient of the liquid concentration is essentially horizontal whereas the relative velocity $\mathbf{v}_{l}-\mathbf{v}_{s}$ is essentially vertical. Therefore their dot product remains small. Finally the only significant driving force for macrosegregation lies in the last term associated with the compression of the solid phase. Comparing Figure 14(c) and Figure 9(a), this is clearly revealed, as macrosegregation principally affects regions where liquid fraction is higher than 0.1 and where the maximum values of $\left|\nabla \cdot \mathbf{v}_{s}\right|$ can be found. That also explains that macrosegregation principally forms in the punching region and has a limited extension apart from this area. This can be seen in Figure 14 where the time evolution of the vertical extent of the segregated zone is limited.

Figure 15 illustrates from a qualitative and a quantitative point of view the final macrosegregation in both cases $\mathrm{N}-1$ and N-9. As already commented with Figure 2, the two micrographs shown in the top line of Figure 15 indicate a marked segregation in case $\mathrm{N}-1$ and no clear trend of segregation for trial N-9. This is confirmed by the measurement profiles obtained by EPMA, for species $\mathrm{Mn}$ and $\mathrm{P}$ along horizontal lines on the transverse surface shown in Figure 2, around the punching height. In the case $\mathrm{N}-1$, a significant depletion in $\mathrm{Mn}$ and $\mathrm{P}$ is measured in the central region of the ingot: the relative variations in concentration are $-15 \%$ for $\mathrm{Mn}$ and $-60 \%$ for $\mathrm{P}$. As expected, the segregation is more marked for $\mathrm{P}$, for which the partition coefficient is smaller (cf Table 2). Indeed, a lower partition coefficient leads to a higher ratio of liquid vs solid concentrations within the mush, so that the magnitude of the macrosegregation is increased. In case N-9, EPMA profiles do not show a clear evidence of a central macrosegregation, confirming its absence on the micrograph.

Regarding the profiles issued from the numerical simulation, in case $\mathrm{N}-1$, they show a central depletion with relative variations of $-8 \%$ for $\mathrm{Mn}$ and $-28 \%$ for $\mathrm{P}$. In case $\mathrm{N}-9$, no significant macrosegregation is calculated. Thus, the numerical simulation results show the same trends as the measurements: more intense central macrosegregation for $\mathrm{P}$ than for $\mathrm{Mn}$; no significant macrosegregation in case N-9. One should add that a numerical test was performed with no punching, i.e. leaving the ingot solidifying with no other external mechanical forces than those created by shrinkage. No macrosegreation was found, the profiles of the solute concentration remaining flat, equal to the nominal alloy composition, in front of the punching tool. Despite this good qualitative agreement with measurements, the intensity of the calculated segregation is found much lower than in reality, roughly by a factor 2. There are several possible causes for these differences, which will be discussed in the following section. 


\subsection{Discussion on the amplitude of macrosegregation}

Experimental observation and "two-phase" numerical simulation reveal the phenomena taking place in the mushy zone: a central negative macrosegregation forms under the concurrent effect of compression of the solid phase, and induced flow of the liquid phase from the punch region toward the top of the ingot. The causes that could explain the too weak intensity of the computed central macrosegregation can be classified in two main categories. The first one comprises the causes for a possible too low enrichment of the liquid phase. The second one comprises the causes for inappropriate solid deformation and induced liquid flow. These two error sources are discussed hereunder.

- Enrichment of the liquid phase. Influence of the microsegregation model

The solutes partition between the liquid phase and the solid phase is crucial since both phases are transported in this study. The solutes enrichment of the liquid phase, or equivalently, the solutes impoverishment of the solid phase, is directly linked to the partition coefficients, which are key variables in any microsegregation model.

Besides the lever rule model, which is used in the simulation, we consider here the Gulliver-Scheil (GS) model, in which complete mixing is assumed in the liquid phase but no diffusion is assumed in the solid phase. In this latter case, and assuming a "closed system" approach (in which the average concentration remains constant all along the solidification for a considered material point), we have for any solute $i$ [28]:

$$
w_{l, i}=\left\langle w_{i}\right\rangle g_{l}^{k_{i}-1} \quad \text { for GS }
$$

In the case of the lever rule (LR), we get, under the same closed system assumption (see also Eq. (16)):

$$
w_{l, i}=\frac{\left\langle w_{i}\right\rangle}{g_{l}+\left(1-g_{l}\right) k_{i}} \quad \text { for LR }
$$

The evolution of the variation of the average concentration in the solid phase as a function of the liquid fraction can be derived easily from the total mass balance of solute specie $i$ $\left\langle w_{i}\right\rangle=w_{l, i} g_{l}+\left(1-g_{l}\right) w_{s, i}$ and Eqs (20)-(21). The respective expressions are as follows:

$$
\begin{array}{ll}
w_{s, i}=\left\langle w_{i}\right\rangle \frac{1-g_{l} k_{i}}{1-g_{l}} & \text { for GS } \\
w_{s, i}=\left\langle w_{i}\right\rangle \frac{k_{i}}{g_{l}+\left(1-g_{l}\right) k_{i}} & \text { for LR }
\end{array}
$$

Figure 16 shows the evolution of the relative variation of the average solute concentration in the solid phase for $\mathrm{Mn}$ and $\mathrm{P},\left(w_{s, i}-w_{i 0}\right) / w_{i 0}$, according to the two microsegregation 
models with $w_{i 0}$ the nominal alloy composition replacing the average solute content $\left\langle w_{i}\right\rangle$. The effect of the partition coefficient can be seen by comparing the evolutions for $\mathrm{Mn}$ and $\mathrm{P}$. Additionally, for each species, the effect of the microsegregation model can also be seen. As expected, the plots for $\mathrm{P}$ are found below those for $\mathrm{Mn}$. As regards the liquid fraction effect, the lower the liquid fraction is, the higher the relative concentration in the solid phase, and so the lower the amplitude of the relative variation. In the case $\mathrm{N}-1$, the maximum liquid fraction calculated at punch start is 0.39 , as presented in Table 3. From Figure 16, the relative variation of the concentration in the solid phase for $\mathrm{Mn}$ and $\mathrm{P}$ is estimated in the case of LR as -0.14 and -0.50 , respectively. This leads to a ratio between these variations of about 3.6 , at punch start.

Looking now at the simulation results, it is found that the maximum relative variations of concentration, after punching, are -0.076 and -0.282 for $\mathrm{Mn}$ and $\mathrm{P}$, respectively (see Figure 15). Thus, the ratio of these variations is around 3.7, very close to the initial ratio before punching. This is fully consistent, as during the $6 \mathrm{~s}$ of the punching stage, the enriched liquid phase is simply transported through the mush: the ratio P/Mn is kept unchanged. Besides, it is worth noting that this ratio is found around 4 for the EPMA measurements $(-0.15$ and -0.60 for $\mathrm{Mn}$ and $\mathrm{P}$, respectively). This good agreement on the ratio between the amplitude of segregation for $\mathrm{Mn}$ and $\mathrm{P}$ indicates that simulation captures well the relative segregation for each species.

Another issue is the concentration in the solid phase itself. At punch start, according to Table 3, the liquid fraction is $g_{l, \text { start }}=0.39$. The average Mn concentration in the solid phase is $w_{s, \text { start }}=0.86 w_{0}$. This latter value is computed from Eq. (23) or deduced from Figure 16 following the LR approximation. Similarly, the average Mn concentration in the liquid phase can be deduced using Eq. (21), which yields $w_{l, \text { start }}=1.22 w_{0}$. From the simulation, the liquid fraction after punching was computed: $g_{l, \text { end }}=0.17$. Note that it corresponds to an increase by $36 \%$ in solid fraction, i.e. $(1-0.17) /(1-0.39)=1.36$. The simulation also shows that this compaction of the solid phase is associated with an almost pure vertical transport of the fluid that can still circulate in the mushy zone. Evaluation of the Mn segregation index after punching with respect to the nominal composition $w_{0},\left(\langle w\rangle-w_{0}\right) / w_{0}$, is then possible considering the total mass balance of solute. Assuming the composition of the two phases unchanged during the short punching time $(6.5 \mathrm{~s})$, we have, at the end of punching:

$$
\langle w\rangle_{\text {end }}=g_{l, \text { end }} w_{l, \text { start }}+\left(1-g_{l, \text { end }}\right) w_{s, \text { start }}
$$

This leads to a segregation index after punching equal to -0.08 for Mn. This value is very close to the minimum read for the computed relative $\mathrm{Mn}$ concentration profile which is displayed in Figure 15(b1), showing that the estimations provided by the present simple analysis are found quite close to the more sophisticated numerical simulation. As stated before, this result yet underestimates macrosegregation, the minimum exhibited in Figure 15(b1) for the measured segregation profiles for Mn being - 0.15 . It should be noted here that it was checked that numerical simulation shows almost no evolution of the segregation profiles between the end of punching and complete solidification. Actually, after punching the permeability is low enough to prevent any significant fluid flow. Therefore, the simple 
estimations calculated above after punching can be reasonably compared to the measurements done on fully solidified ingots.

Let's now examine what would be the situation considering GS instead of LR. Assuming the same initial liquid fraction at punch start, $g_{l, s t a r t}=0.39$, and applying Eqs (20) and (22), the Mn concentration in the liquid and solid phases would be $w_{l, \text { start }}=1.32 w_{0}$ and $w_{s, \text { start }}=0.79 w_{0}$, respectively. Further assuming the same increase of solid fraction - through compaction - by $36 \%$ in the mushy zone, leading to $g_{l, e n d}=0.17$, the average $\mathrm{Mn}$ concentration obtained by Eq. (24) yields now $\langle w\rangle_{\text {end }}=0.88 w_{0}$, that is a segregation index after punching equal to -0.12 . This value comes closer to observation.

As a conclusion, it can be said that the choice of the microsegregation model has a significant influence on the intensity of the macrosegregation (increasing it by $45 \%$ in the case of Mn). Thus, it might be interesting to consider more sophisticated microsegregation models, like those taking into account partial equilibrium with peritectic transformation [29]. In addition, undercooling effect could be taken into account, providing a more accurate solidification path and initial liquid fraction before punching.

- Influence of solid compression and associated liquid flow

The compression of the solid phase and the liquid flow obviously play a prominent role in solutes distribution, as already underlined when commenting Eq. (19) governing the evolution of average solutes concentration. Consequently, a few parameters are expected to have an impact on the amplitude of segregation. A first set of parameters consists of the constitutive parameters of the solid phase, and among them particularly the viscoplastic consistency $K$ and the compressibility parameter $B$. Indeed a lower value of the consistency, or a greater value of $B$, would favor the compression of the solid phase and then increase the amplitude of macrosegregation. A second set of parameters consists of those governing the permeability of the solid network and so the distribution of liquid flow through it. Assuming Eq. (6) for the isotropic permeability, the only parameter is in fact the secondary dendrite arm spacing $\lambda_{2}$.

In order to test the influence of those parameters, a sensitivity analysis is considered. It consists of three tests for which, all other things being equal, the value of one of the parameters $K, B$ and $\lambda_{2}$ has been changed. The considered changes for each of the coefficients are indicated in Table 4 . They are all expected to induce a more marked negative segregation in the ingot center: viscoplastic consistency divided by two; compressibility coefficient doubled; secondary dendrite arm spacing multiplied by three. The last line of the Table contains the value of the maximum (in absolute value) relative variation of average $\mathrm{Mn}$ concentration obtained in each simulation. As expected, the three test simulations show a more severe central negative macrosegregation, which again shows a good qualitative response of the "two-phase" FE calculation. In comparison with the reference simulation $\mathrm{N}-1$, the magnitude of Mn segregation index is increased by $21 \%$ in simulation S-1 (influence of $K$ ), $18 \%$ in simulation S-2 (influence of $B$ ) and by $8 \%$ in simulation S-3 (influence of $\lambda_{2}$ ). Considering the large variations tested for those parameters, it appears that their influence is effective, but probably lower than the impact of the choice of the microsegregation model, as discussed above. 


\section{Conclusions}

An ingot punch pressing test has been developed to better understand the phenomena affecting the solid shell and the central mushy zone of steel semi-products when crossing the secondary cooling section during continuous casting. The test consists of the punching of one side of the solid shell of a partially solidified steel ingot by an external tool. The present study is focused on the formation of macrosegregation induced by this punching operation. The deformations of the solid shell and of the central mushy zone are simulated numerically. The mechanics of the mushy zone is addressed by a "two-phase" approach, in which the compressible deformation of the solid phase and the liquid flow are solved concurrently, as they are in close interaction. Coupling with the numerical solution of solute mass transfer induced by liquid flow is achieved, thus simulating the occurrence of macrosegregation. A 2D FE method is used to solve all conservation equations in a single model.

Two experimental tests are selected, consisting of two ingots of the same steel grade, but punched at different instants, corresponding to different progressions of their solidification prior to punching. Simulations with the "two-phase" FE model demonstrate the ability to capture the essential phenomena that drive macrosegregation in the ingot punch pressing tests: compression by mechanical deformation of the porous solid phase combined with liquid flow through the permeable medium. The compression and its resulting permeability decrease are more marked for the ingot where solidification was less advanced at the onset of punching. It leads to the formation of intense negative central macrosegregation in the upper half part of this ingot. For the second ingot punch pressing test, deformation was also simulated but it did not generate significant macrosegregation as solidification was more advanced at the onset of pressing, thus hindering solute transport by liquid flow in the mushy zone. Quantitative comparisons between simulated and measured composition profiles demonstrate that the "sponge-like" model [9] for the mechanical behavior of the mushy zone and the proposed "two-phase" numerical resolution $[10,11]$ constitute a step forward on modelling deformation-induced macrosegregation during steel casting processes by combining coupled phenomena. This work constitutes the first validation of modeling efforts started in the sixties [1] to describe the role of thermomechanical deformation on the formation of macrosegregation, latter developed for steels [6-18].

However, the intensity of the predicted macrosegregation remains lower than the one measured in reality. Through the discussion of the results and in the light of sensitivity tests, it appears that the observed differences are mainly due to the type of microsegregation model and to the constitutive model and parameters controlling the compression of the solid phase in the mushy zone. Regarding the first point, the sole lever rule has been used in the present study. The use of the Gulliver-Scheil or alternative microsegregation models could increase the intensity of calculated macrosegregation. As for the mechanics of the mushy zone, the identification of compressibility parameters by separate elementary rheological tests appears to be essential as they also influence significantly the intensity of macrosegregation.

Macrosegregation remains the main defect to be controlled during $\mathrm{CC}$. The present contribution reports efforts to reach quantitative prediction. Regarding applicability to steel continuous casting, it was already shown to be effective in 2D and for a binary alloy, allowing 
the analysis of soft reduction operations carried out on steel slabs at the end of the secondary cooling zone [11]. In addition to the implementation of better microsegregation models, extension to $3 \mathrm{D}$ analysis is necessary to address the continuous casting of slong products, such as billets or blooms, or to capture with better accuracy edge effects, e.g. close to the two lateral narrow faces, in the case of slabs. The achievement of such models is of paramount importance for the understanding and control of the formation of central macrosegregation. It is expected that enhanced modeling capabilities will benefit optimization of actual industrial practices by increasing yield through reducing macrosegregation defects. Achieving more quantitative modeling of macrosegregation and other defects (e.g., hot tearing [19]), has also potential for exploring numerically routes to cast high-alloyed steels with various grades and to reduce the time to production of new alloys. 


\section{References}

1. M. Flemings and G. Nereo, Macrosegregation: Part I, Transactions of the Metallurgical Society of AIME 239 (1967) 1449-1461.

2. M. Wu and A. Ludwig, A three-phase model for mixed columnar-equiaxed solidification, Metall. Mater. Trans. A 37 (2006) 1613-1631.

3. J. Li, M. Wu, A. Ludwig, and A. Kharicha, Simulation of macrosegregation in a 2.45-ton steel ingot using a three-phase mixed columnar-equiaxed model. International Journal of Heat and Mass Transfer 72 (2014) 668-679.

4. M. Založnik, H. Combeau, An operator splitting scheme for coupling macroscopic transport and grain growth in a two-phase multiscale solidification model: Part I - Model and solution scheme, Computational Materials Science 48 (2010) 1-10.

5. T.-T.-M. Nguyen, H. Combeau, M. Založnik, M. Bellet, Ch.-A. Gandin, Multi-scale finite element modelling of solidification structures by a splitting method taking into account the transport of equiaxed grains, Proc. MCWASP XIV, 14th Int. Conf. on Modeling of Casting, Welding and Advanced Solidification Processes, Awaji Island, Japan, 21-26 June 2015, H. Yasuda (ed.), IOP Conference Series: Materials Science and Engineering 84 (2015) article 012007, 10 pages.

6. K. Miyazawa, K. Schwerdtfeger, Macrosegregation in Continuously Cast Steel Slab: Preliminary Theoretical Investigation on the Effect of Steady State Bulging, Arch. Eisenhuttenwes 52 (1981) 415-422.

7. T. Kajitani, J. M. Drezet, M. Rappaz, Numerical simulation of deformation induced segregation in continuous casting of steel, Metall. Mater. Trans. A 32 (2001) 1479-1491.

8. J. Domitner, M. Wu, A/ Kharicha, A. Ludwig, B. Kaufmann, J. Reiter, T. Schaden, Modeling the effects of strand surface bulging and mechanical softreduction on the macrosegregation formation in steel continuous casting, Metall. Mater. Trans. A 45 (2014) 1415-1434.

9. G. Lesoult, Ch.-A. Gandin, N.T. Niane, Segregation during solidification with spongy deformation of the mushy zone, Acta Materialia 51 (2003) 5263-5283.

10. V.D. Fachinotti, S. Le Corre, N. Triolet, M. Bobadilla, M. Bellet, Two-phase thermomechanical and macrosegregation modelling of binary alloys solidification with emphasis on the secondary cooling stage of steel slab continuous casting processes, Int. J. Num. Meth. Eng. 67 (2006) 1341-1384.

11. M. Bellet, A two-phase 2D finite element model for macrosegregation in steel continuous casting, Proceedings of the 5th Decennial Int. Conf. on Solidification Processing (2007) 424-427. Ed. H. Jones, The University of Sheffield, Sheffield, United Kingdom.

12. B. Rivaux, Modélisation multi - échelle des structures de grains et des ségrégations dans les alliages métalliques, Ph.D. Thesis. MINES ParisTech, Paris, France (2011).

13. H. Sato, T. Kitagawa, K. Murakami, T. Kawawa, Tetsu to Hagane 61 (1975) S471.

14. K. Miyamura, A. Ochi, K. Kanamaru, N. Kaneko, Tetsu to Hagane 62 (1976) S482.

15. K. Marukawa, M. Kawasaki, T. Kimura, S. Ishimura, Tetsu to Hagane 64 (1978) S661.

16. K. Narita, T. Mori, K. Ayata, J. Miyazaki, M. Fujimaki, Tetsu to Hagane 64 (1978) S152.

17. Y. Sugitani, M. Nakamura, H. Kawashima, M. Kawasaki, Tetsu to Hagane 66 (1980) S193.

18. M. Wintz, M. Bobadilla, M. Jolivet, Hot craking during solidification of steels - effect of carbon, sulphur and phosphorus, La Revue de Métallurgie 4 (1994) 105-114. 
19. T. Koshikawa, M. Bellet, Ch.-A. Gandin, H. Yamamura, M. Bobadilla, Metallurgical and materials transactions 47A (2016) 4053-4067.

20. J. Ni, C. Beckermann, A volume-averaged two-phase model for transport phenomena during solidification, Metall. Mater. Trans. B 22 (1991) 349-361.

21. M. Bellet, V.D. Fachinotti, ALE method for solidification modelling, Comput. Meth. Appl. Mech. Eng. 193 (2004) 4355-4381.

22. M. Bellet, O. Jaouen, I. Poitrault, An ALE-FEM approach to the thermomechanics of solidification processes with application to the prediction of pipe shrinkage, Int. J. Num. Meth. Heat Fluid Flow 15 (2005) 120-142.

23. P. Shi, TCS steels/Fe-alloys database V6.0, Thermo-Calc Software AB, Stockholm, Sweden (2008).

24. Thermo-Calc, TCCS manuals, Thermo-Calc software AB, Stockholm, Sweden (2013).

25. Iron and Steel Institute of Japan: Mechanical behavior in Continuous Casting, ISIJ, NCID:BN03702225 (Citation Information by National institute of informatics: CiNii), (1985).

26. A. Palmaers, A. Etienne, J. Mignon, Calculation of the Mechanical and Thermal Stresses in Continuously Cast Strands, Stahl und Eisen 99 (1979) 1039-1050.

27. British Iron and Steel Research Association: Physical constants of some commercial steels at elevated temperatures (based on measurements made at the National Physical Laboratory, Teddington, United Kingdom), Butterworths Scientific Publications, London, United Kingdom (1953).

28. J.A. Dantzig, M. Rappaz, Solidification, EPFL Press (2009).

29. T. Koshikawa, C.A. Gandin, M. Bellet, H. Yamamura, M. Bobadilla, Computation of phase transformation paths in steels by a combination of the partial- and para-equilibrium thermodynamic approximations, ISIJ Int, 54 (2014) 1274-1282. 
Table 1 Measured nominal compositions and experimental punching conditions

\begin{tabular}{|c|c|c|c|c|c|c|c|c|c|c|}
\hline & \multicolumn{6}{|c|}{$\begin{array}{l}\text { Nominal composition } \\
\text { (wt.pct) }\end{array}$} & \multirow{2}{*}{$\begin{array}{c}\text { Mold } \\
\text { removal } \\
{[\mathrm{s}]}\end{array}$} & \multirow{2}{*}{$\begin{array}{c}\text { Punching } \\
\text { start } \\
{[\mathrm{s}]}\end{array}$} & \multirow{2}{*}{$\begin{array}{c}\text { Displace- } \\
\text { ment } \\
{[\mathrm{mm}]}\end{array}$} & \multirow{2}{*}{$\begin{array}{l}\text { Velocity } \\
{\left[\mathrm{mm} \mathrm{s}^{-1}\right]}\end{array}$} \\
\hline & $\mathrm{C}$ & $\mathrm{Si}$ & $\mathrm{Mn}$ & $\mathrm{P}$ & $\mathrm{S}$ & $\mathrm{Al}$ & & & & \\
\hline $\mathrm{N}-1$ & 0.20 & 0.22 & 1.50 & 0.021 & 0.007 & 0.039 & 590 & 792 & 13 & 2.0 \\
\hline N-9 & 0.20 & 0.22 & 1.49 & 0.021 & 0.010 & 0.039 & 590 & 881 & 9 & 2.0 \\
\hline
\end{tabular}

Table 2 Partition coefficient and liquidus slope for solutes [23, 24]

\begin{tabular}{lccccc}
\hline & $\mathrm{C}$ & $\mathrm{Si}$ & $\mathrm{Mn}$ & $\mathrm{P}$ & $\mathrm{S}$ \\
\hline Partition coefficient $k_{i}$ & 0.162 & 0.639 & 0.703 & 0.282 & 0.027 \\
Liquidus slope $m_{i}\left[\mathrm{~K}\right.$ (wt.pct) $\left.{ }^{-1}\right]$ & -81 & -12 & -5 & -29 & -34 \\
\hline
\end{tabular}

Table 3 Comparison of calculated liquid fraction at ingot center when punching starts

\begin{tabular}{lcc}
\hline & $\mathrm{N}-1$ & $\mathrm{~N}-9$ \\
\hline Calculated liquid fraction & 0.39 & 0.12 \\
Calculated temperature, at TC-1 nominal location $\left[{ }^{\circ} \mathrm{C}\right]$ & 1493 & 1455 \\
Temperature measured by TC- $1\left[{ }^{\circ} \mathrm{C}\right]$ & $1487 \pm 4$ & $1461 \pm 4$ \\
\hline
\end{tabular}

Table 4 Summary of sensitivity tests. N-1 is the reference simulation while S-1, S-2, and S3 are three sensitivity tests.

\begin{tabular}{lrrrr}
\hline & $\mathrm{N}-1$ & $\mathrm{~S}-1$ & $\mathrm{~S}-2$ & $\mathrm{~S}-3$ \\
\hline Multiplier applied to the viscoplastic consistency $K$ & & & & \\
over the solidus temperature & 1.0 & $\underline{0.5}$ & 1.0 & 1.0 \\
Multiplier applied to the compressibility coefficient $B$ & 1.0 & 1.0 & $\underline{2.0}$ & 1.0 \\
Secondary dendrite arm spacing $\lambda_{2}[\mu \mathrm{m}]$ & 300 & 300 & 300 & $\underline{1000}$ \\
\hline Maximum relative variation in concentration for Mn & -0.076 & -0.092 & -0.090 & -0.082 \\
Relative variation with respect to reference & - & $+21 \%$ & $+18 \%$ & $+8 \%$ \\
\hline
\end{tabular}



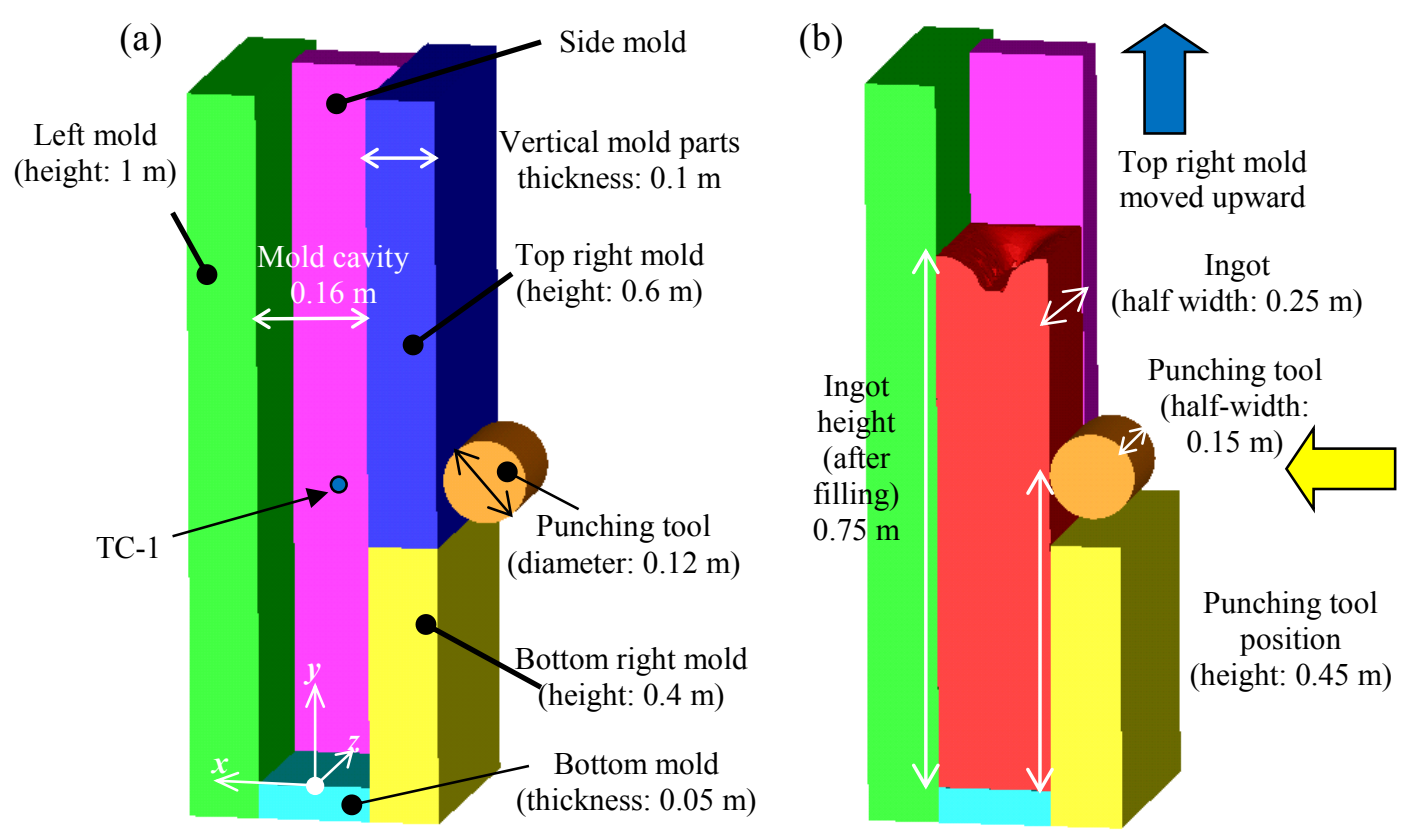

Figure 1. Schematic of the ingot punching test developed at Nippon Steel \& Sumitomo Metal Corporation showing (a) initial state and (b) punching stage after the top right mold was removed. The configuration shown is half of the setup, considering symmetry with respect to the central transverse section through the whole system. A thermocouple (TC-1) is placed at coordinates $(0,0.43,0.06)$, with reference frame centered at the top surface of the bottom mold plate. 
(a)

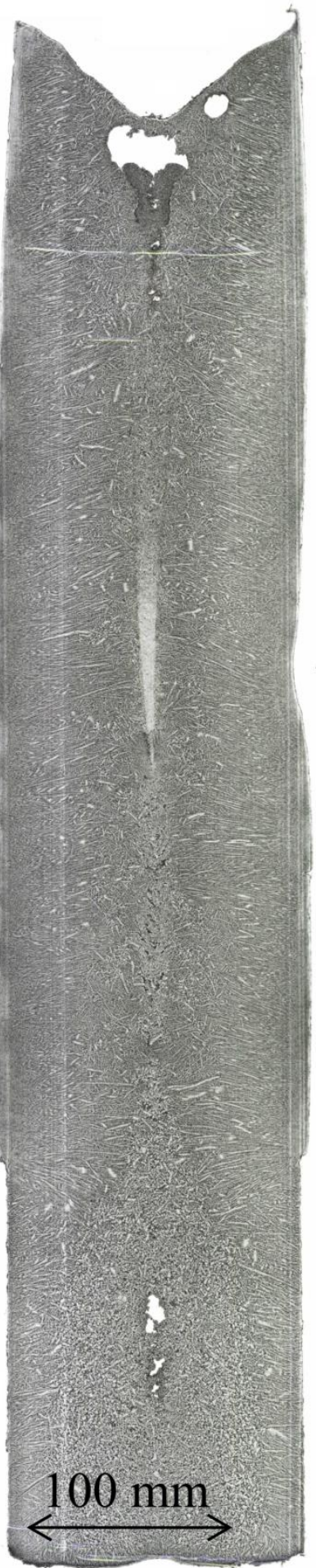

(b)

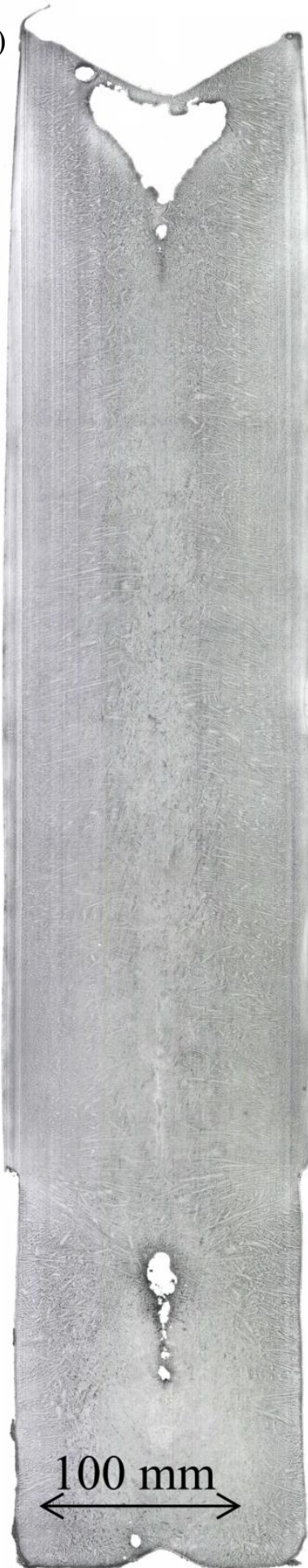

Figure 2. Micrograph at central transverse section of (a) N-1 and (b) N-9 ingots. Macrosegreation is qualitatively revealed by the variations of the grey level. The print og the punching tool is visible on the right hand side in these images. 


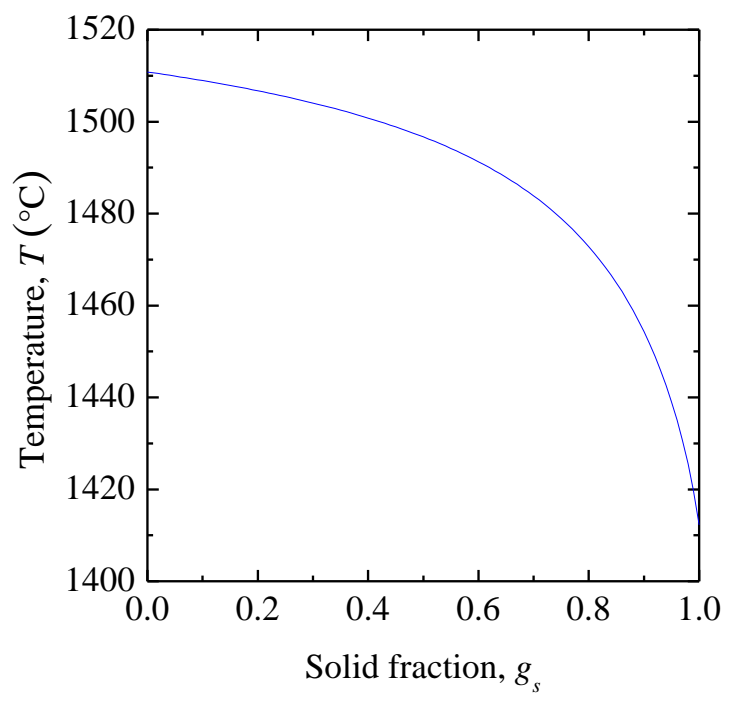

Figure 3. Solidification path with nominal steel composition N-1 given in Table 1, by use of Thermo-Calc with the TCFE6 database $[23,24]$ and assuming the lever rule approximation (Al is omitted in the calculation). 
(a)

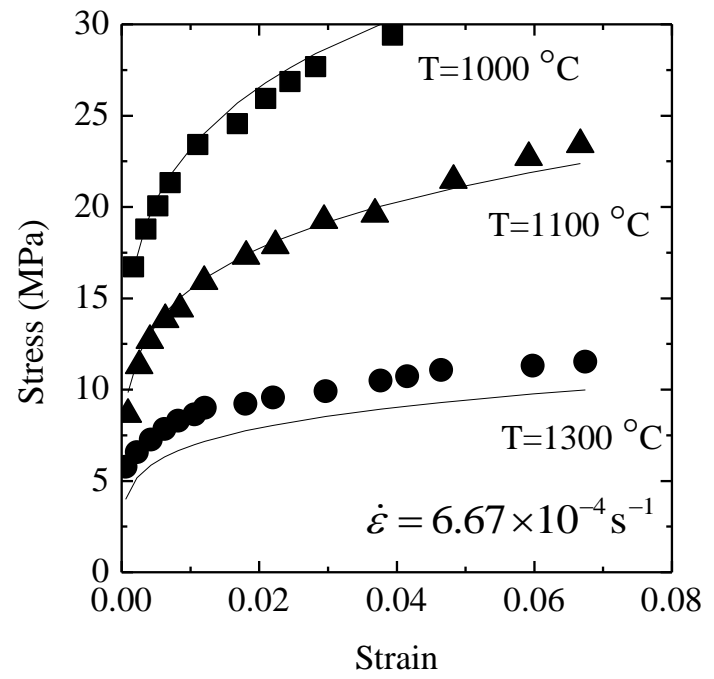

(c)

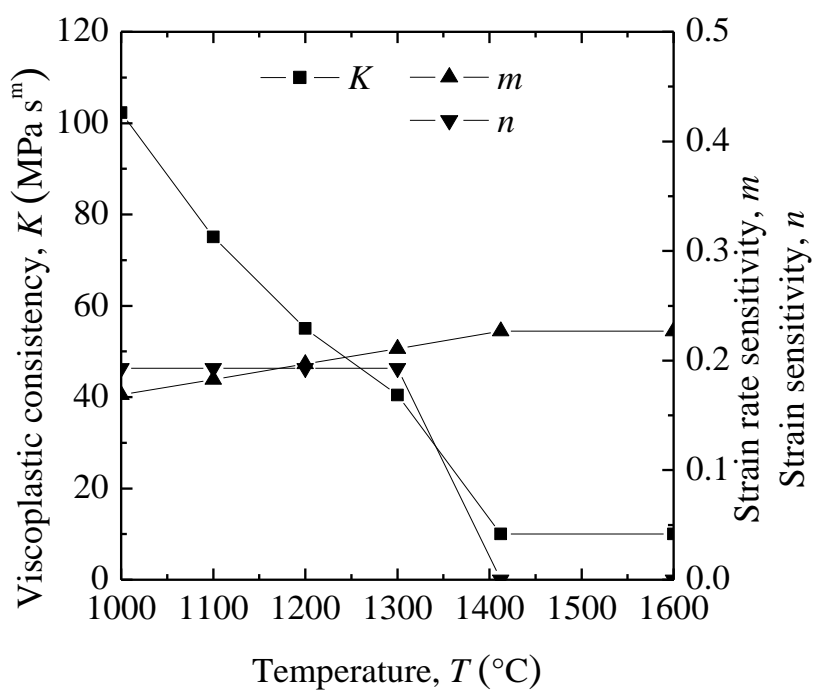

(b)

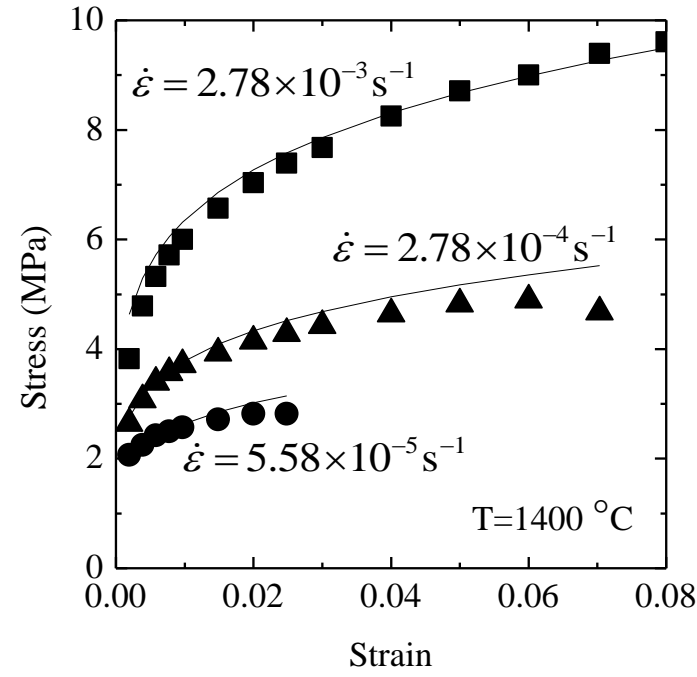

Figure 4. Rheological behavior as strain-stress $(\bar{\varepsilon}-\bar{\sigma})$ relation (a) for 3 temperatures from $1000{ }^{\circ} \mathrm{C}$ to $1300{ }^{\circ} \mathrm{C}$ at constant strain rate, $6.67 \times 10^{-4} \mathrm{~s}^{-1}$ and (b) at a higher temperature, $1400{ }^{\circ} \mathrm{C}$, for 3 different strain rates established by means of (marks) high temperature tensile tests $[25,26]$ and (curves) calculations based on Eq. (13).. The temperature dependence of constitutive parameters for Eq. (13), assuming full equilibrium solidification, are given in (c). 


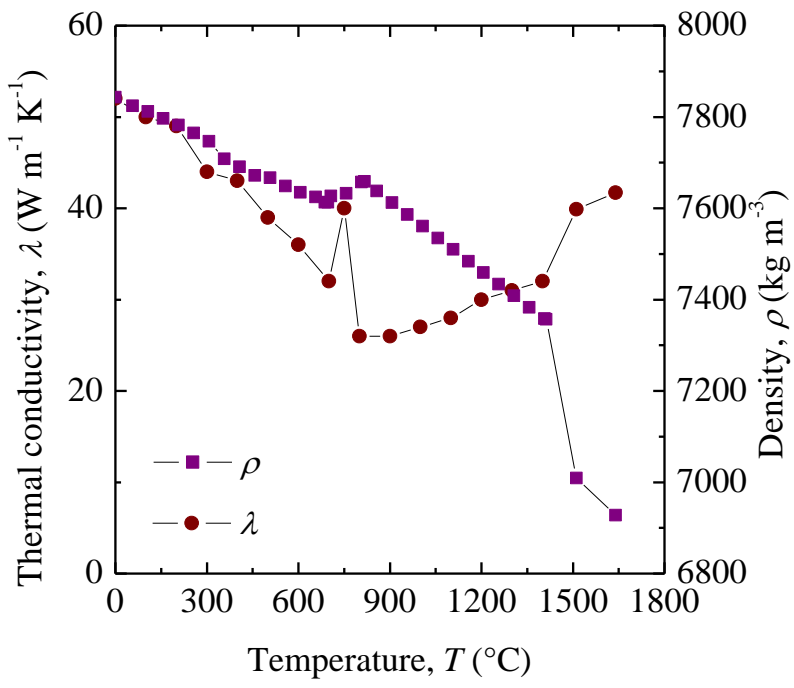

Figure 5. Temperature dependent average properties for thermomechanical simulations including density while assuming full equilibrium [23, 24] and thermal conductivity [27]. 


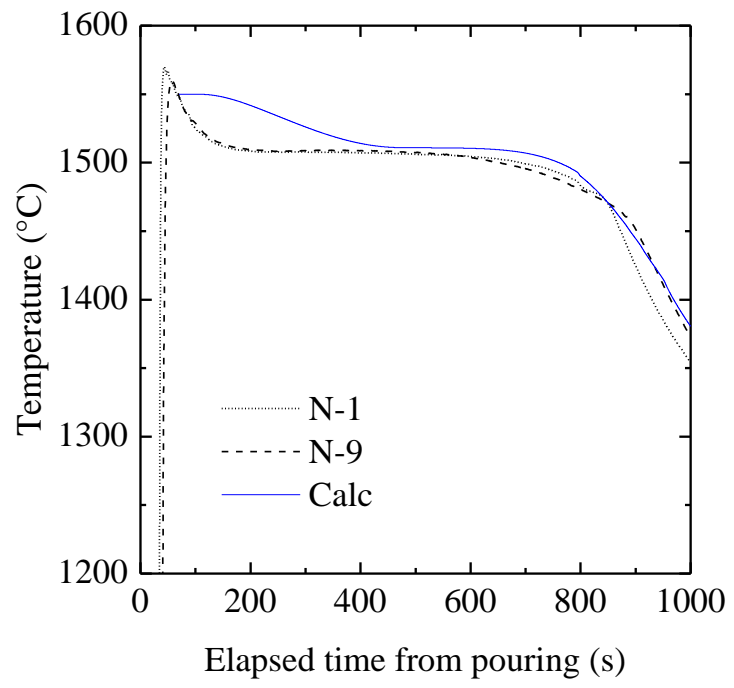

Figure 6. Measured cooling history recorded at thermocouple TC-1 (Figure 1) during experiments $\mathrm{N}-1$ and $\mathrm{N}-9$, and calculated with the finite element simulation at the nominal location of the thermocouple. 
(a)

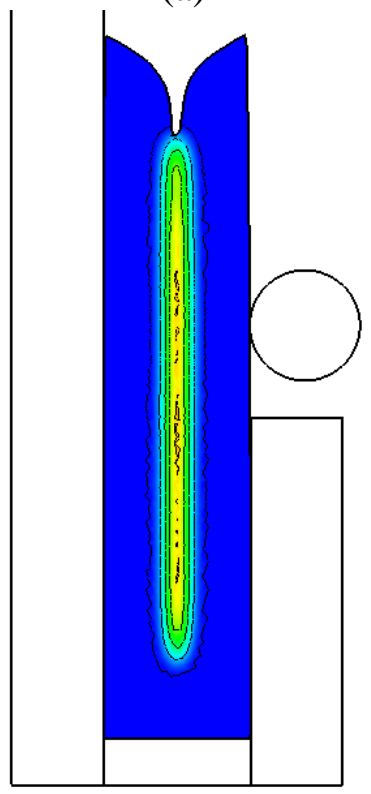

(b)

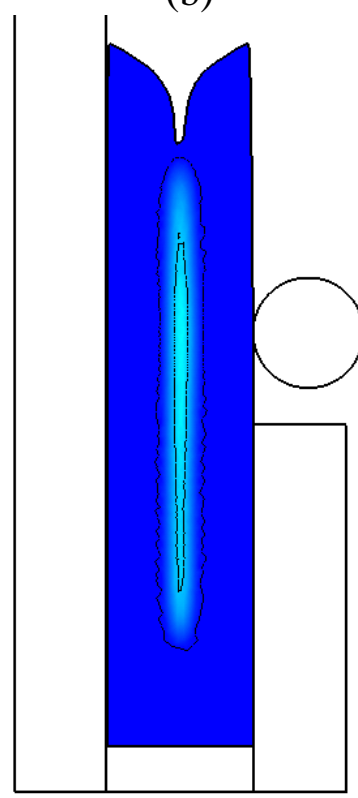

\section{5}

$g_{l}$

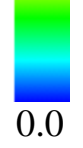

Figure 7. Calculated shape of the ingot and distribution of the liquid fraction just before punching (a) at time $792 \mathrm{~s}$ (corresponding to trial N-1) and (b) at time $881 \mathrm{~s}$ (corresponding to trial N-9). 


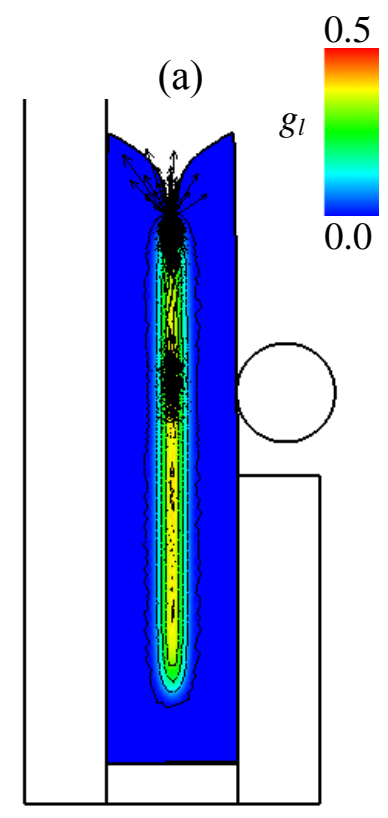

(b)

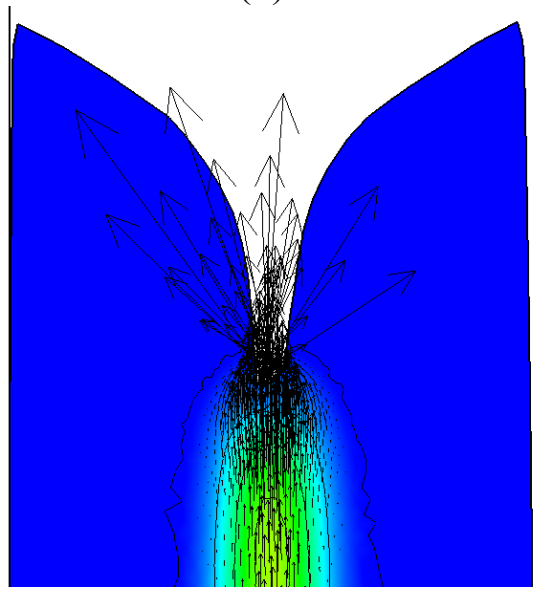

(c)

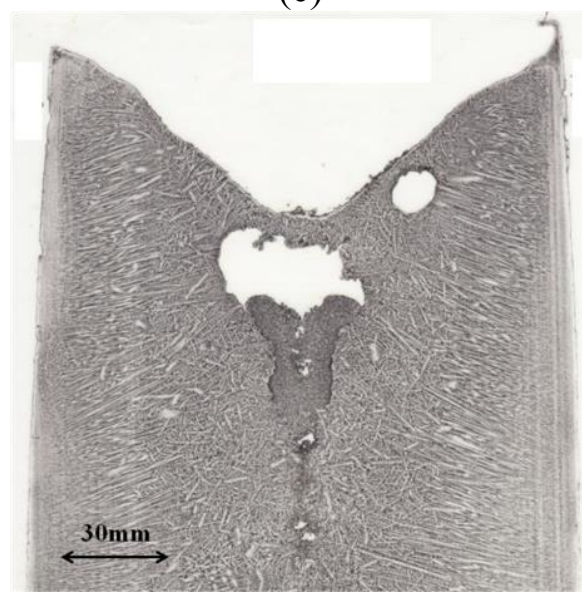

Figure 8. Simulated and observed ingot shape showing (a) a global view of its deformation at time $792.4 \mathrm{~s}(0.4 \mathrm{~s}$ after punch start) for trial $\mathrm{N}-1$ and (b) a zoom in the top region with shrinkage pipe to be compared with (c) observation. The simulation also shows (color map) the distribution of the liquid fraction and (black contours) isofractions of liquid, as well as the (arrows) the relative velocity of the liquid phase with respect to the solid one, $\mathbf{v}_{l}-\mathbf{v}_{s}$. The darker region at the center of the micrograph is expelled liquid in the primary shrinkage cavity as a result of punching. 
(a) $\mathbf{v}_{s}$ (horizontal comp., $\mathrm{m} \mathrm{s}^{-1}$ )

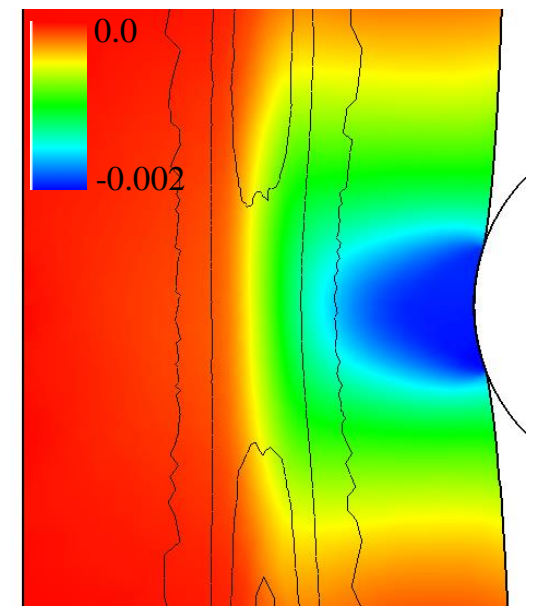

(b)

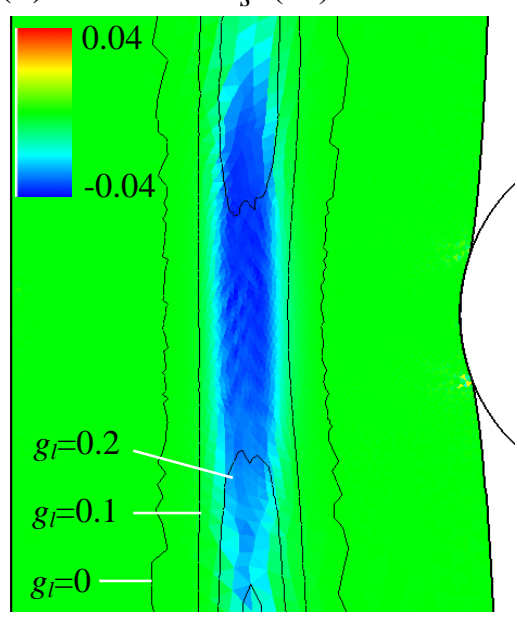

(c) $\mathbf{v}_{l}-\mathbf{v}_{s}$ (vert. comp., $\mathrm{m} \mathrm{s}^{-1}$ )

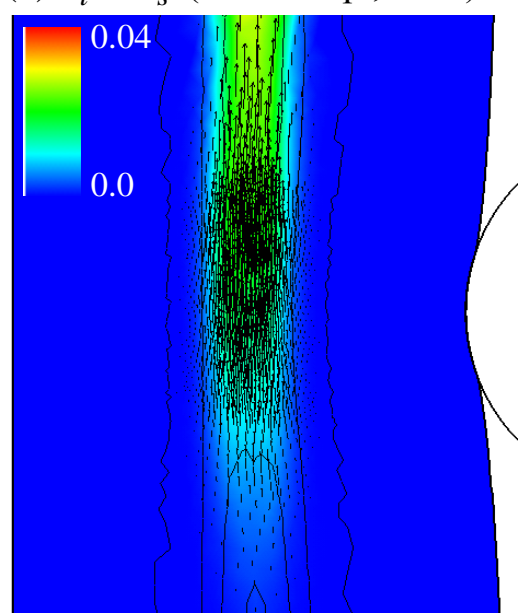

Figure 9. Central region in the simulation of ingot N-1, $6 \mathrm{~s}$ after punch start, showing (a) the distribution of the horizontal component of the velocity of the solid phase $\mathbf{v}_{s}$, (b) $\nabla \cdot \mathbf{v}_{s}$ with evidence of negative values in the mushy zone at the height of the punch tool and (c) the vertical component of the relative velocity of the liquid phase with respect to the solid one, $\mathbf{v}_{l}-\mathbf{v}_{s}$. The simulation also shows (black contours) isofractions of liquid, from 0 to 0.3 , and (arrows) the vector field $\mathbf{v}_{l}-\mathbf{v}_{s}$. 
(a) Time $=1 \mathrm{~s}$ after punch start

(b) Time $=4 \mathrm{~s}$ after punch start

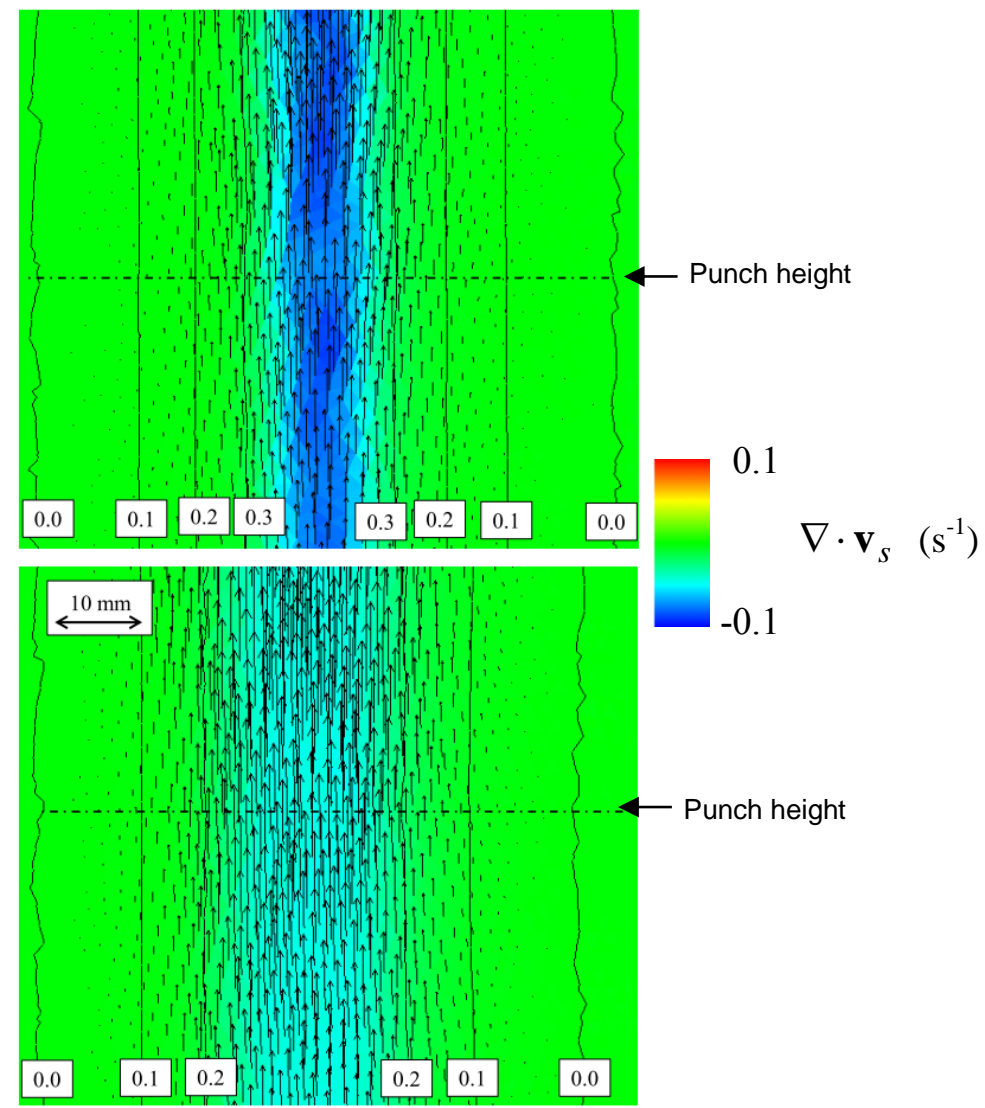

Figure 10. Distribution of the divergence of the solid phase velocity field, together with the isolines for the liquid fraction, and a vector representation of the relative velocity field of the liquid phase with respect to the solid one: $\mathbf{v}_{l}-\mathbf{v}_{s}$. Information is given for trial N-1 during punching (a) $1 \mathrm{~s}$ and (b) $4 \mathrm{~s}$ after punch start. The horizontal dot line indicates the height of the punching tool. 


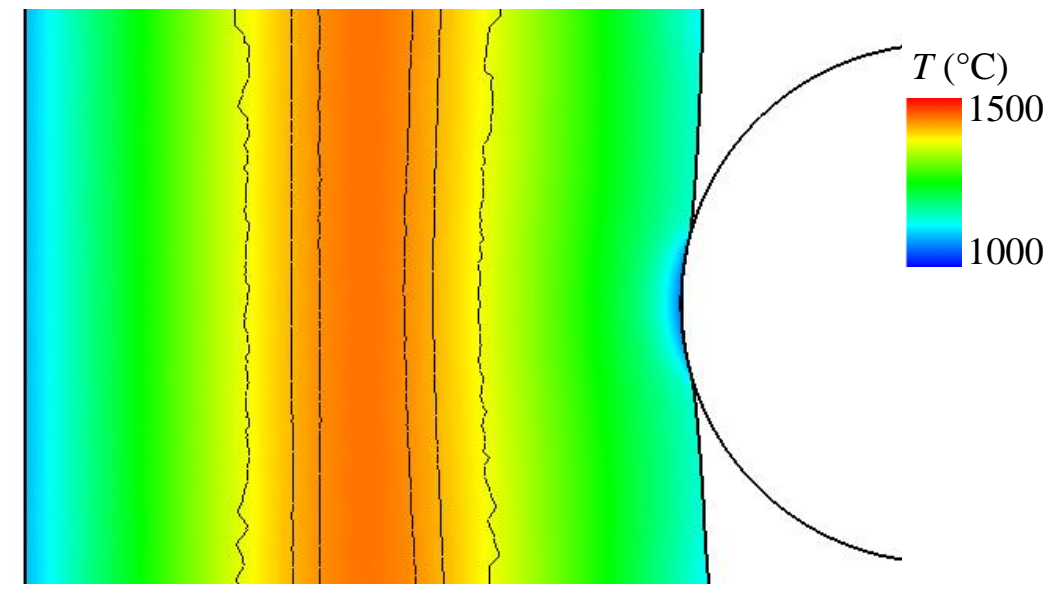

Figure 11. Chill effect during punching shown $4 \mathrm{~s}$ after punching start with liquid fraction isolines. 


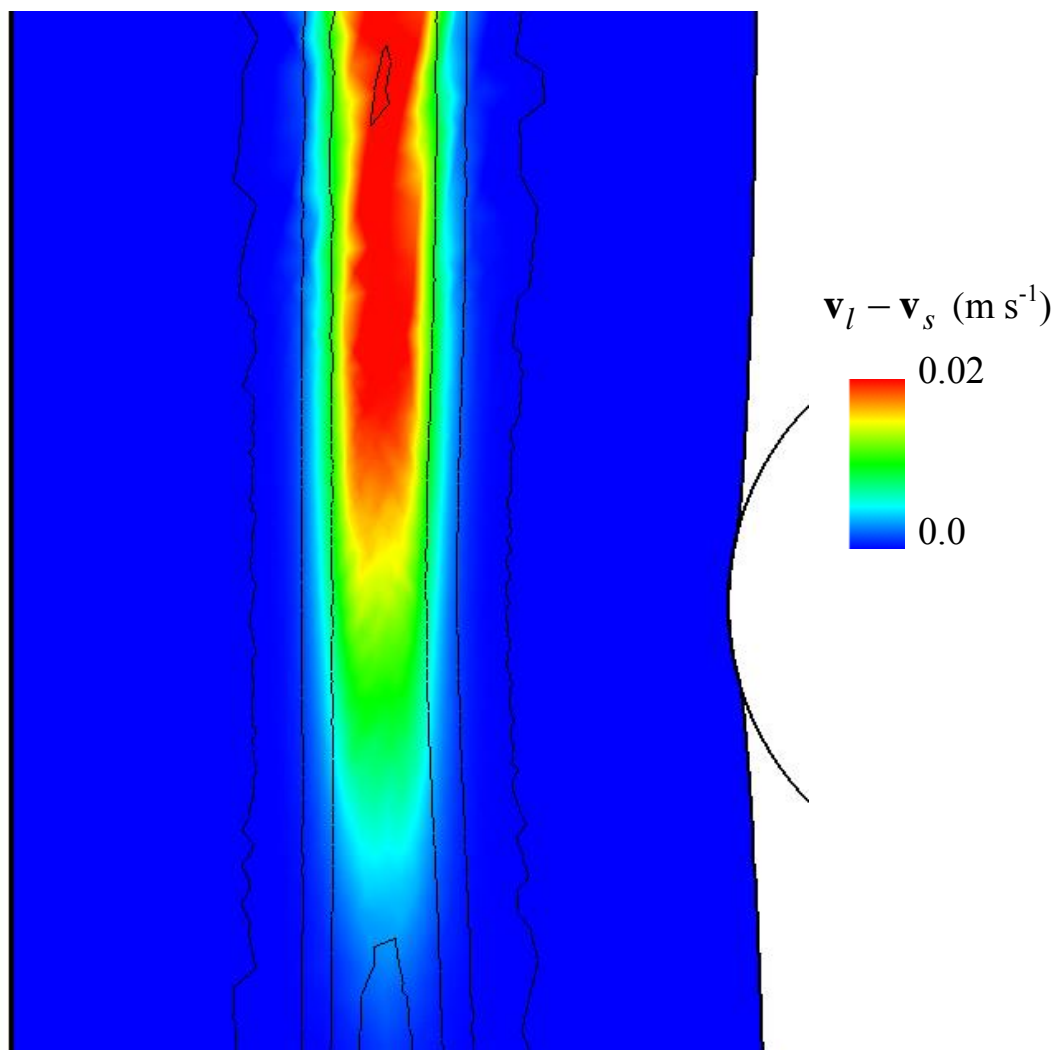

Figure 12. Relative velocity field along vertical direction with the isolines of liquid fraction 4 $\mathrm{s}$ after the start of punching. 
(a) Time $=1 \mathrm{~s}$ after punch start

(b) Time $=4 \mathrm{~s}$ after punch start

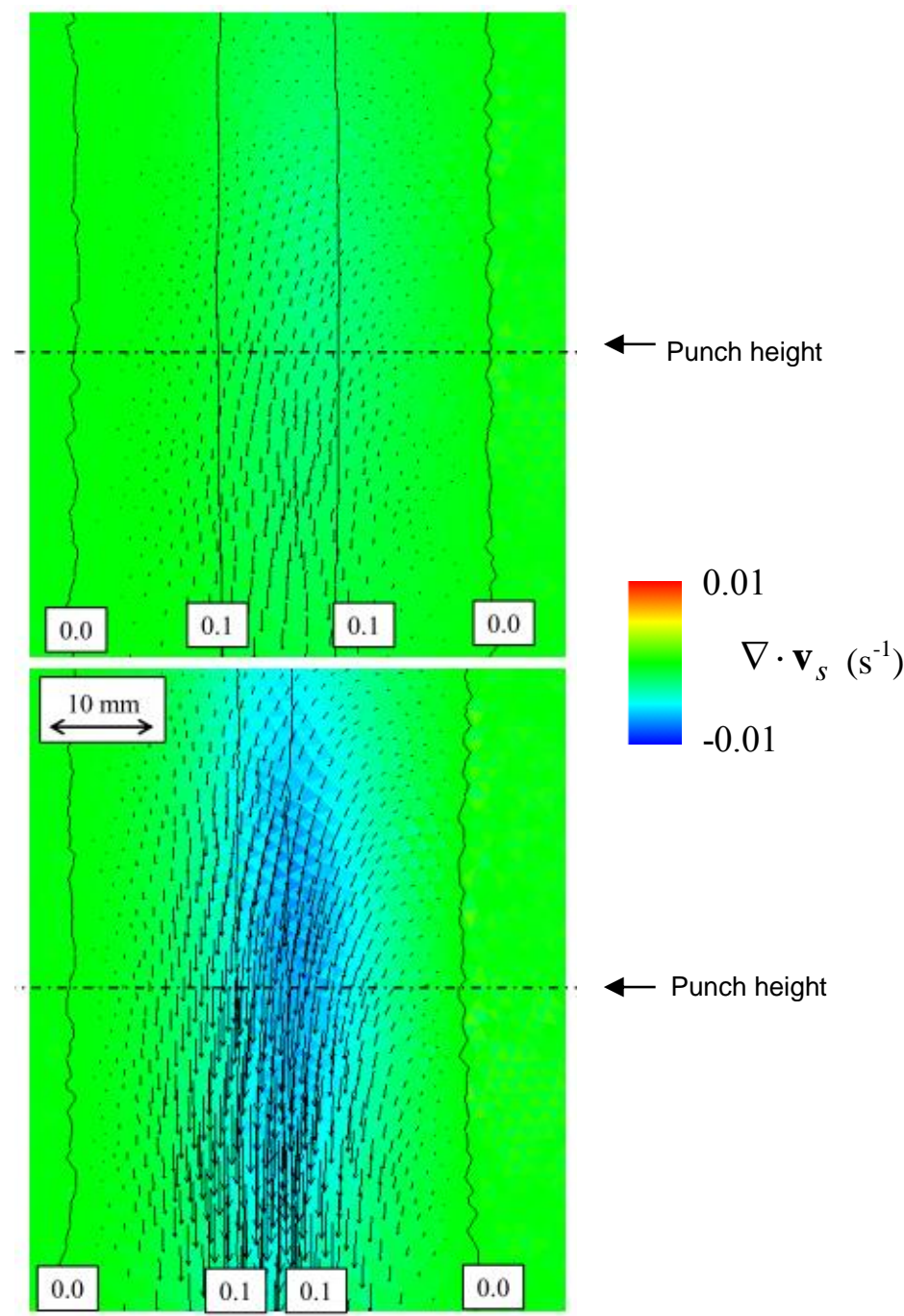

Figure 13. Simulation of trial N-9. The punching is triggered at a later stage of solidification. Comparison can be done with Figure 10 for trial N-1. Same caption as for Figure 10. 


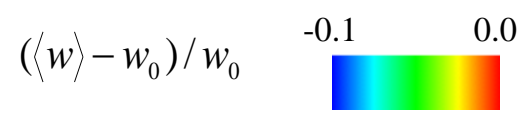

(a) after $1 \mathrm{~s}$

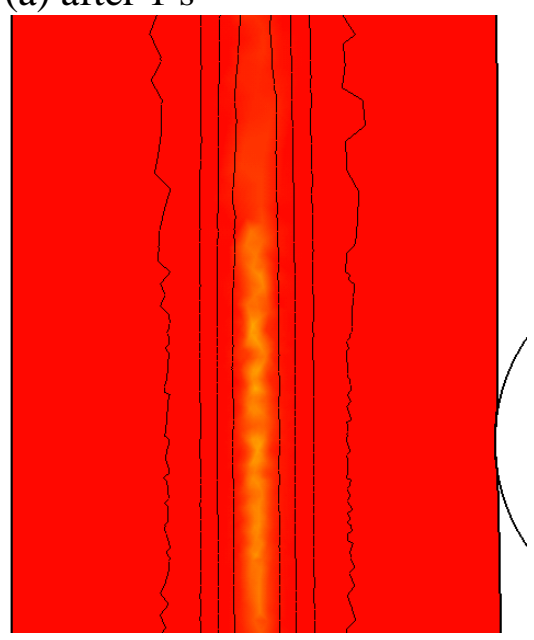

(b) after $3 \mathrm{~s}$

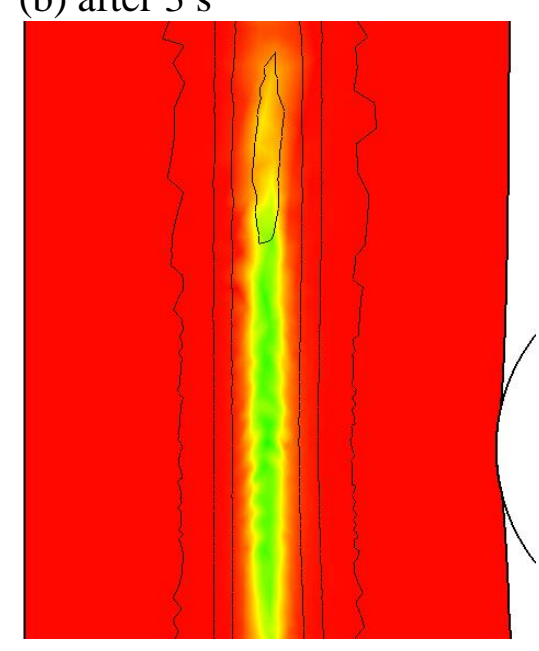

(c) after $6 \mathrm{~s}$

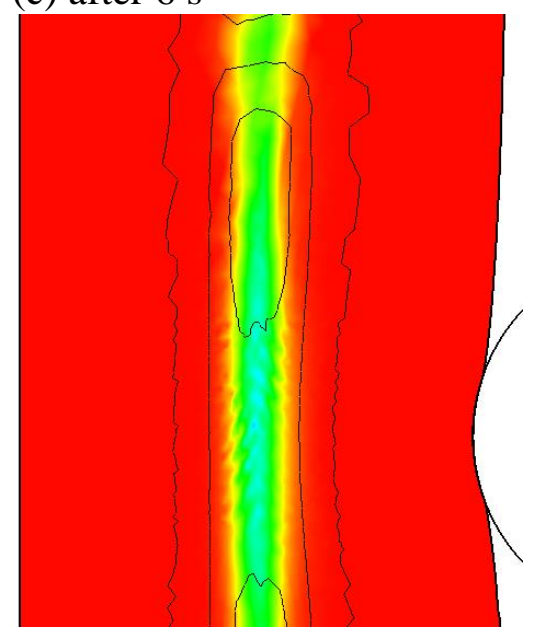

Figure 14. Formation of a negative macrosegregation zone for $\mathrm{Mn}$ at the core of the ingot for trial N-1 (a) $1 \mathrm{~s}$, (b) $3 \mathrm{~s}$ and (c) $6 \mathrm{~s}$ after punching start. The distribution of the relative difference in mass concentration with respect to the nominal one, $\left(\langle w\rangle-w_{0}\right) / w_{0}$, is represented, as well as the black isocontours for the liquid fraction. 
(1) $\mathrm{N}-1$

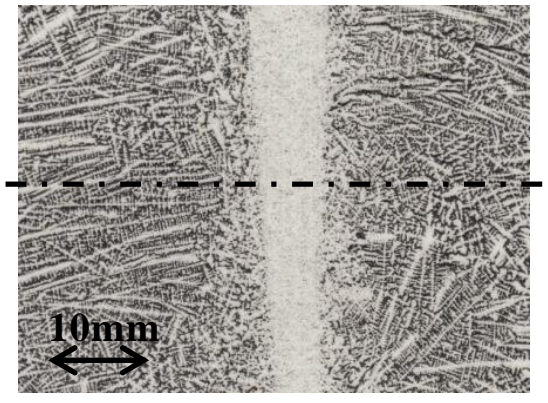

(b)

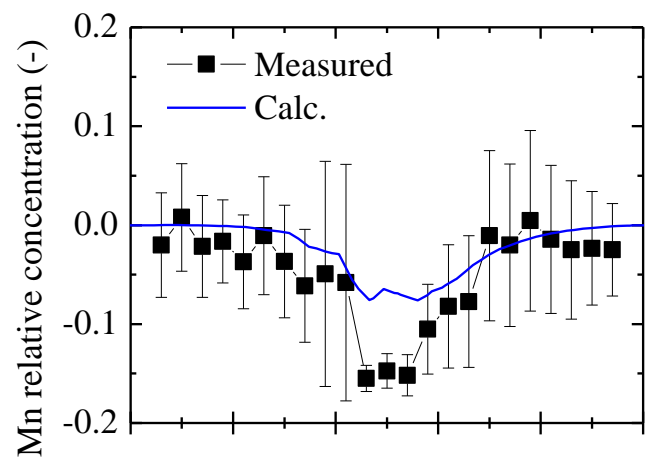

(c)

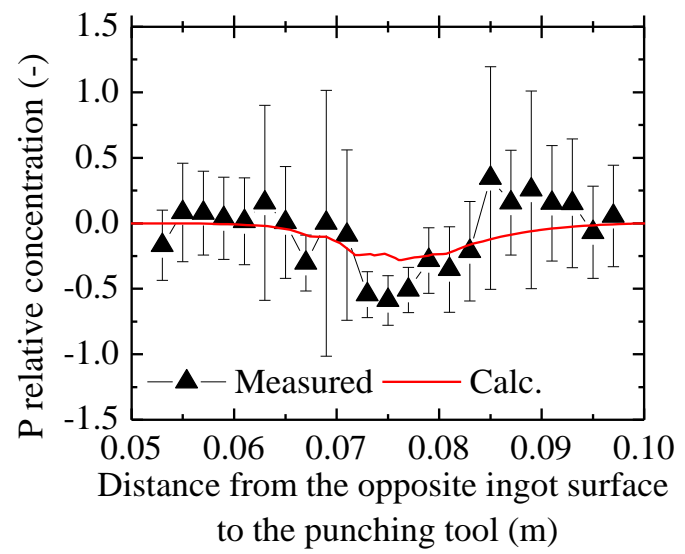

(2) N-9
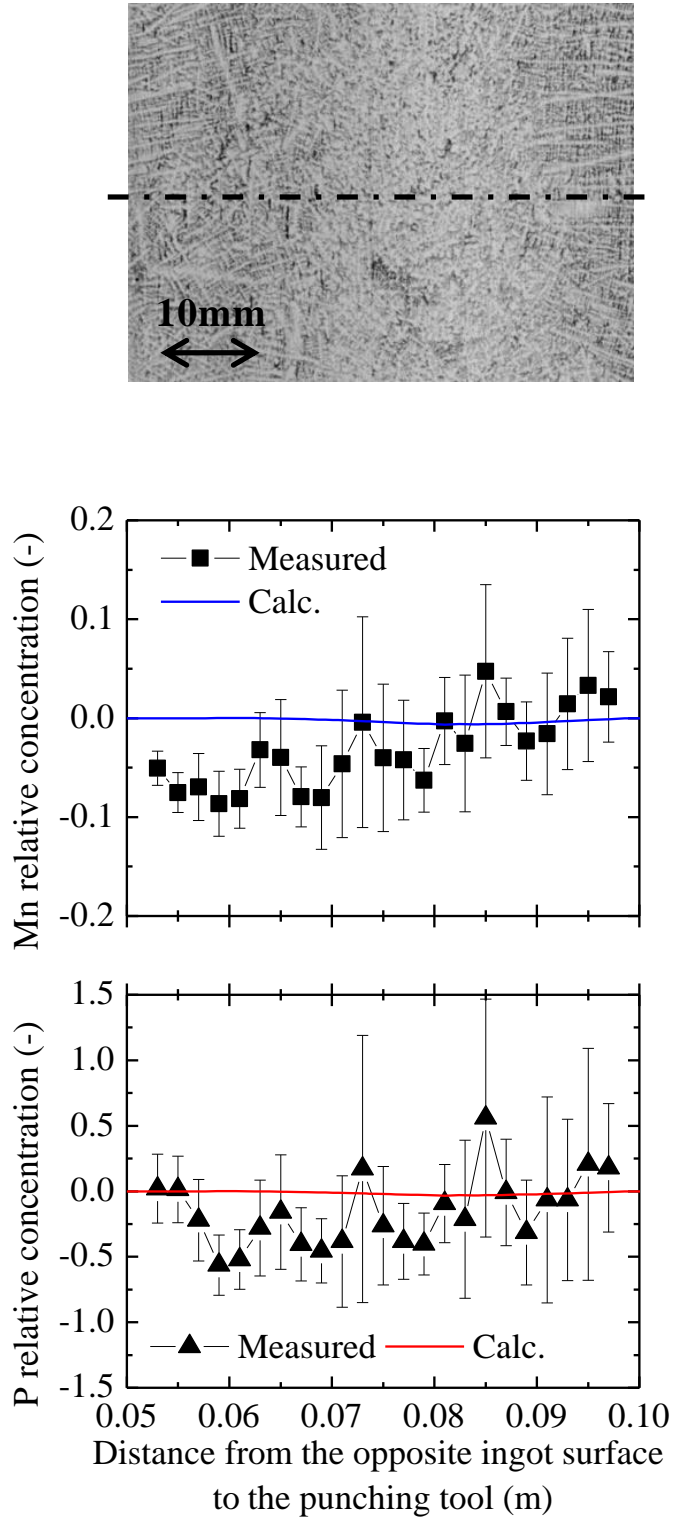

Figure 15. Comparison of calculated and measured final segregation profiles in case of trial (1) N-1 and (2) N-9 showing (a) micrographs at punch height, and the relative variation in concentration $\left(\left\langle w_{i}\right\rangle-w_{i 0}\right) / w_{i 0}$ where $w_{i 0}$ stands for the nominal initial composition in solute $i$ for (b) Mn and (c) P. Profiles are plotted through the thickness of the ingot, at punch height, the mid-section after punching being around $75 \mathrm{~mm}$ from the ingot surface opposite to the punching side. EPMA measurements are indicated by (b) black squares and (c) triangles, while the continuous curves are extracted from the finite element simulations. Error bars indicate standard deviations. 


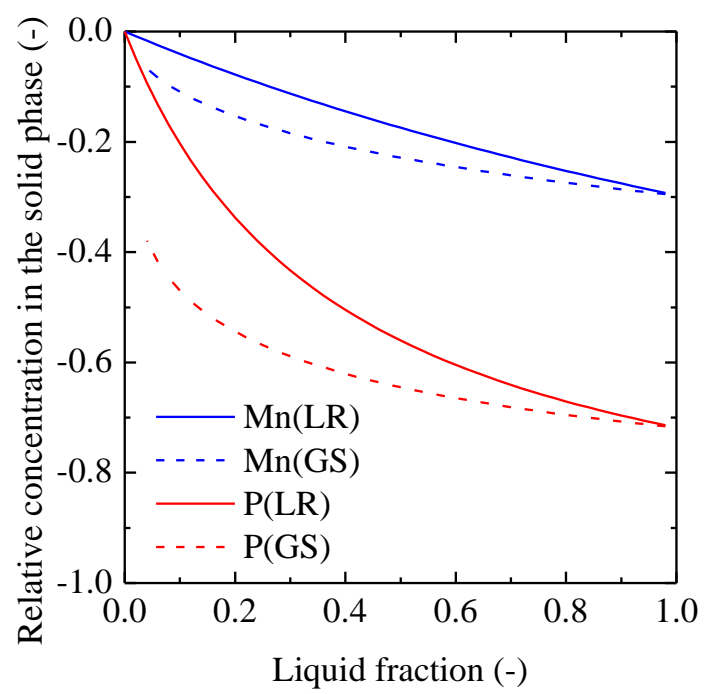

Figure 16. Relative variation of average solute concentration in the solid phase as a function of the liquid fraction. The dependence is plotted for solutes $\mathrm{Mn}$ and $\mathrm{P}$, and for two microsegregation models: (LR) lever rule and (GS) Gulliver-Scheil. The relative variation of the concentration in the solid phase is calculated as $\left(w_{s, i}-w_{i 0}\right) / w_{i 0}$ where $w_{i 0}$ is the concentration of solute $i$ at the beginning of solidification. 